\title{
مؤشرات ودوافع الحراك المهنى فى المجتمع البدوى
}

\author{
احمد انور رفاعى \\ قسم الدراسات الاجتماعية - مركز بحوث الصحراء
}

Received: Aug. 7, 2019

Accepted: Sep. 3, 2019

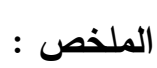

استهافت الدراسة التعرف على مؤشلات الحراك الاجتماعى والمهنى فى المجتمع البلوى عبر جيلين (الابناء و الاباء

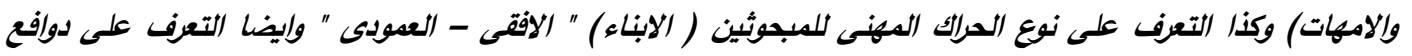

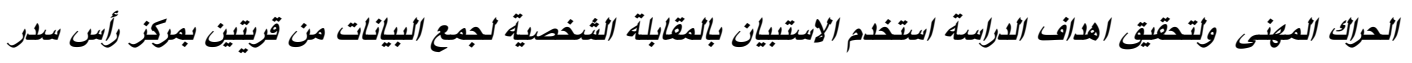

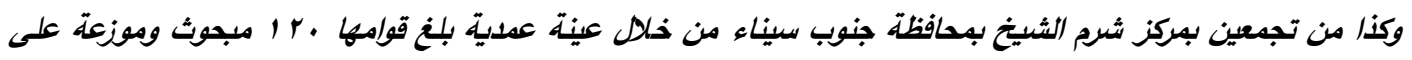

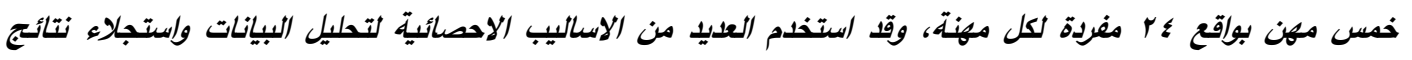

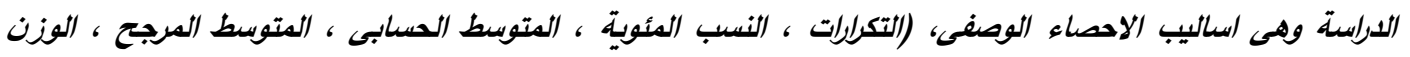

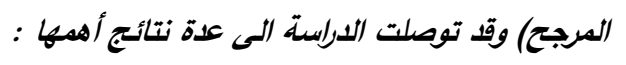

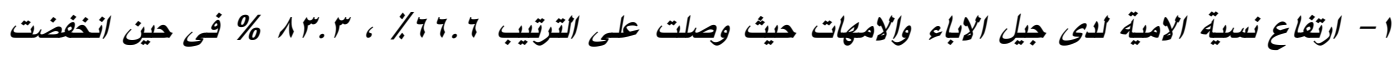

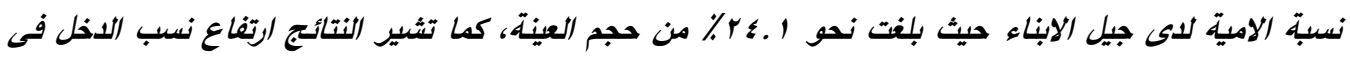

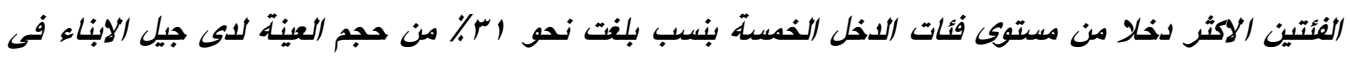

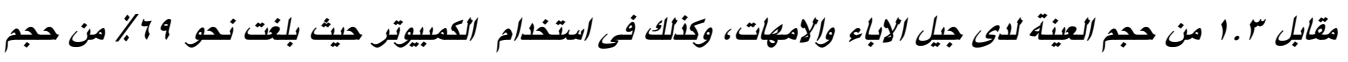

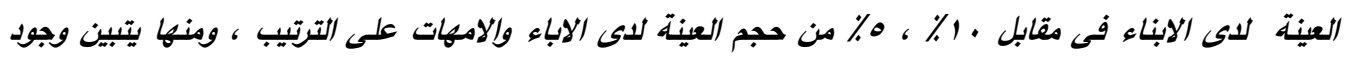

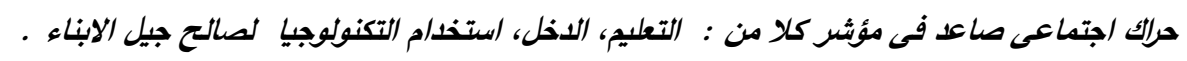

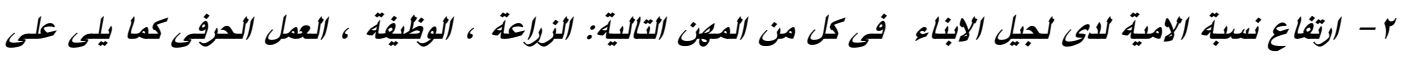

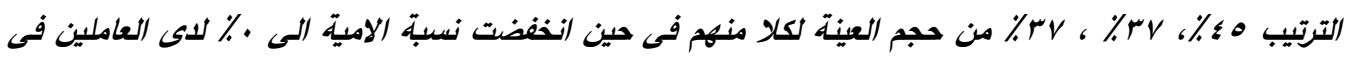

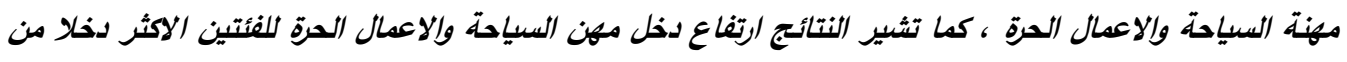

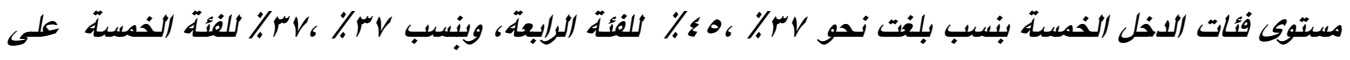

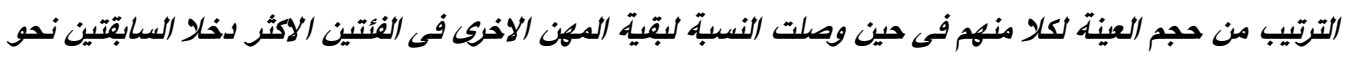

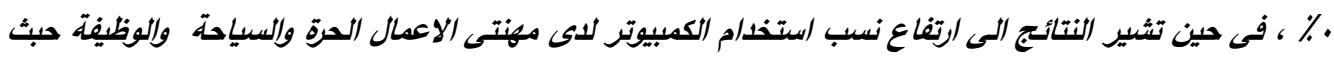

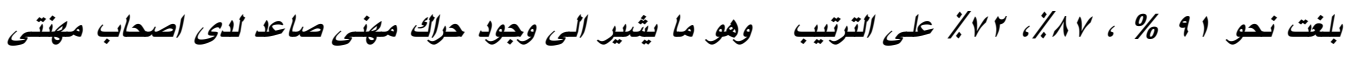

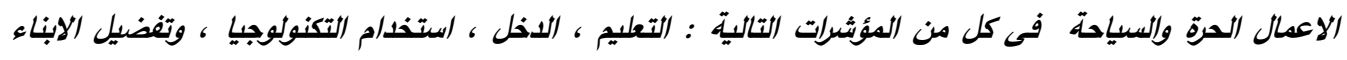
الععل فى مهن جليدة عن مهن الاباء والاجداد.

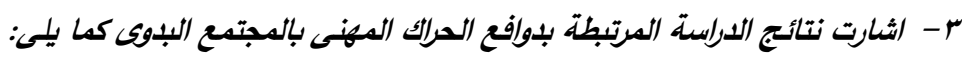

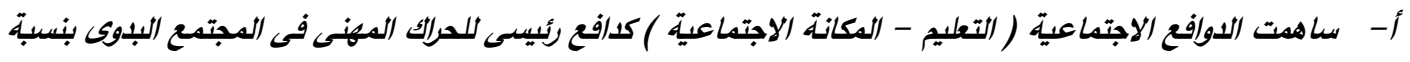

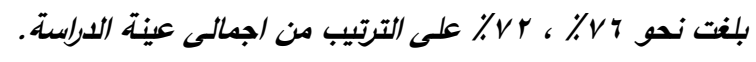

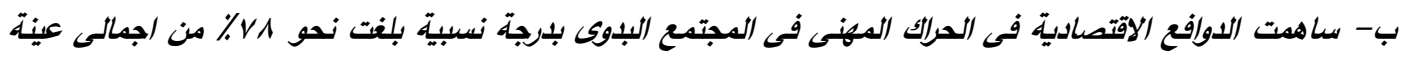
الدراسة. 


\section{A. A. Refae}

ت- شاركت الدوافع البيئية فى الحراك المهنى فى المجتمع الباوى بقوة نسبية بلغت نحو س V \% من اجمالم عينة الدراسة

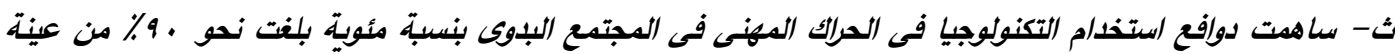
اللداسة . الكلمات الدالثة: الحراك الاجتماعى، الدراك المهنى ، الانفتاح الجغرافى ، الافتتاح الثقافى

أن سمات الطبيب أو التكوين الاجتماعي للطبيب تختلف

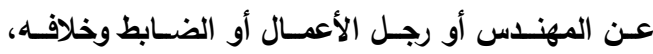

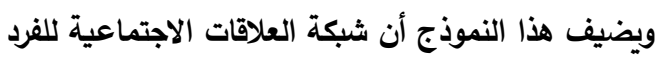

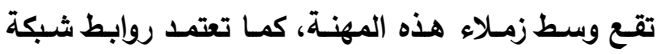
العلاقات الاجتماعية على أوجه التشابه بين المجموعات

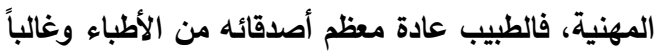

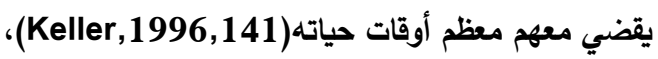
وقد تمتد هذه العلاقات إلى أوقات الفراغ ويقضوات معظم

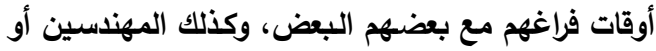
الضباط وغيرهم، بـل وتمتد هذه العلاقات إلى العلاقات

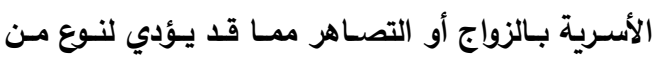

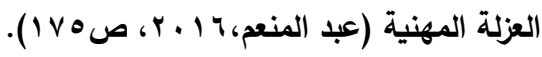
وترتبط المهن بكلمة "العمل"، وقد ركز العلماء

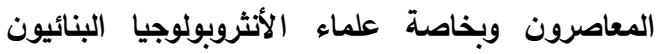

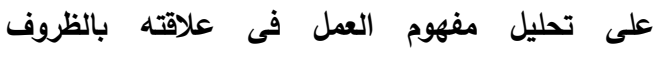
الايكولوجية والاجتماعية المختلفة ، بحيث يدرس النثاط الإقتصادى الذى يطلق عليه أسم "العمل" فى كل أبعاده الاجتماعية كنظام من النظم التى تؤلف فى تفاعلى الاعلها

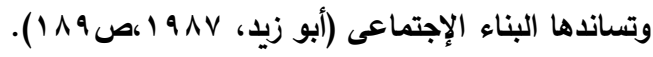
وتعتبر مهنة الرعى من أهم سمات النشاط الاقتصادي فى المجتمعات الصحراوية التقليدية، فهي لفئي تعكس ظروف الحياة الطبيعية والمناخية ، ويوجد قطاع

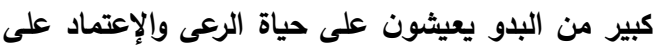

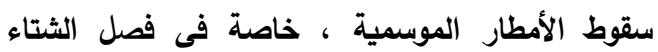

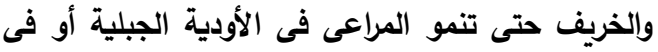

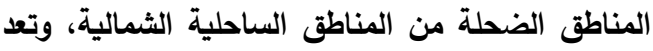

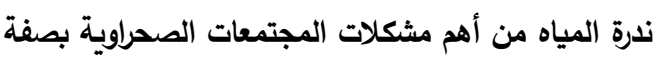

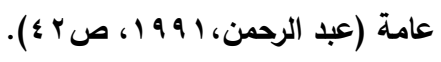

مقدمة ومشكلة الدراسة

أن التعرف على البيئة بما تحتوى من ثروات طبيعية، ومعرفـة مكونـات هذه البيئة من تربـة، ومنـاخ، ونبـات، وحيوان، ومصادر المياه، وعلاقة كل هذا بالنشاط البشرى

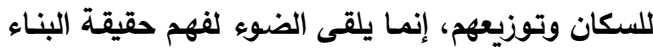

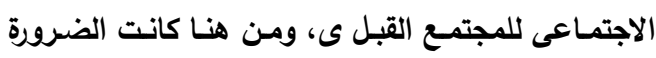
للإثشارة إلى الملامـح الايكولوجيا للمنطقة بإعتبارها إطاراً لفهم عدد من الظواهر وثيقة الصلة بالتغيرات الاجتماعية والثقافية وإلمتأثرة أساساً بالبيئة (إسماعيل، .99 19. 19. ص ץ §). وتـؤثر هذه الملامـح الايكولوجيـة فـى تثـكيل

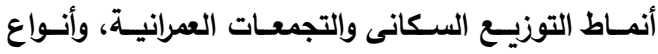

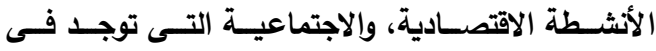
المجتمع الصحراوى، وتنطبق كثيراً من ملامسح الايكولوجيا على العديد من المجتمعات الصحراوية فى العالم، وتتمثل في طبيعة الصحراء الجافة، وندرة المياه، وقسوة العوامل المناخية والتضاريسية ، ويعتبر الإهتمام بتحليل الملامسح الايكولوجية، أو البيئية الطبيعية عاملاً هامـاً فى تحليل

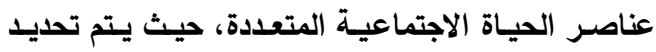

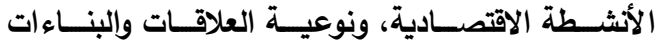

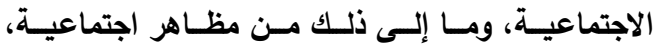

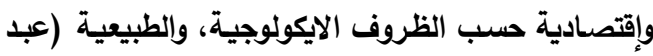

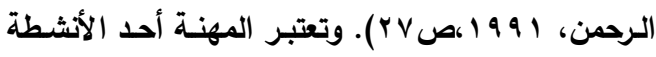
الاقتصادية الهامـة، و ظاهرة إجتماعية تنتشر فى كافـة

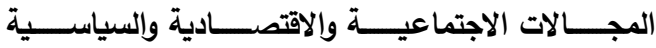

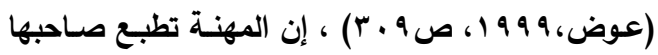

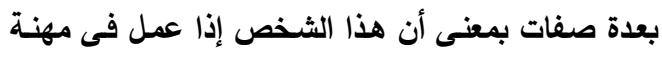

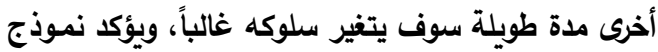

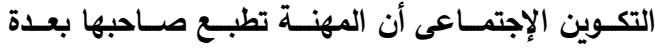

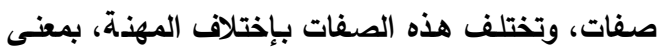


والصناعات البدوية، والزخرفية، والعلاقات العامة،

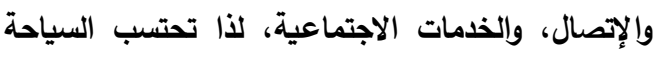

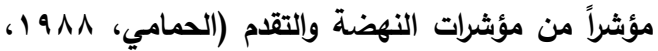

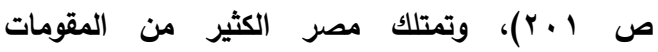

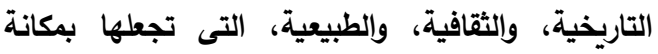

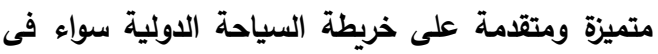
مجال الآثار حيث توجد بمصره \%٪ من آثار العالم، أو سياحة الثواطئ، والسياحة الترفيهية، والسياحة

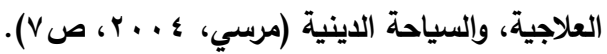
وتعد السياحة هي النشاط الإقتصادي الرئيسي بمدينة

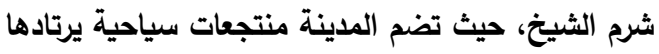
الزائرون من جميع أنحاء العالم، وتثتهر بأنها أحد مراكز

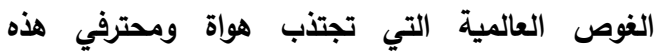
الرياضة، كما تثتمل على مطار دولي، غير أن نسبة

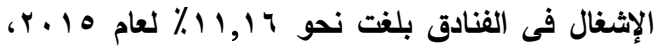
نتيجة الأحاث الإرهابية، وعدم الإستقرار الأمني بالمنطقة لإنة

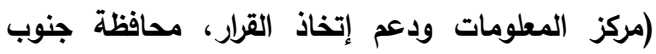

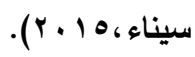

ان التنوع فى المهن وادخال مهن جديدة فى

المجتمع البدوى هو ما يؤدى الى احداث نوع من الحراك

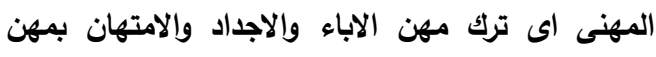

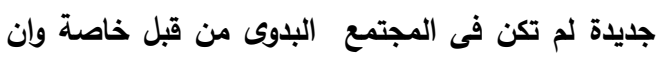
كانت هذه المهن جاذبة ماديا ومعنويا، وبذلك تثكل

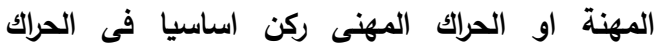
الاجتماعى الذى يعتبر ظاهرة اجتماعية ينتقل من خلاهها

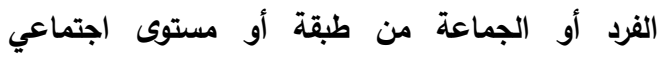

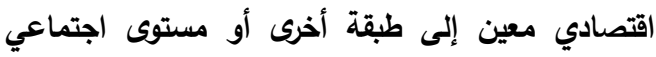

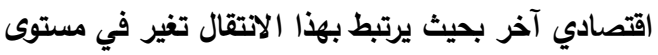

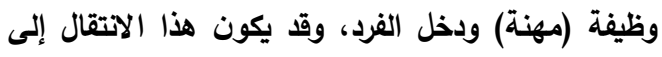

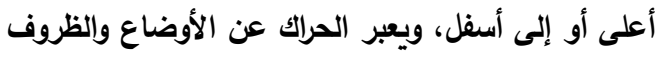

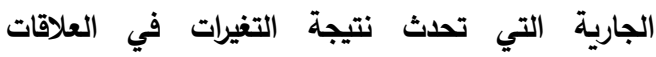
الاجتماعية وفقا لاختلاف المكان والزمان، حيث يتحرك الفرد أو الجماعة من مكانة اجتماعية معينة إلى مكانة

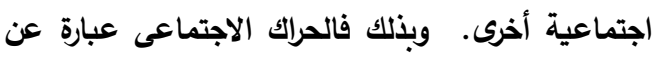

ولمهنة الزراعة دور هام فى بناء وتكوين المجتمعات

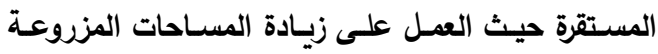
على أرض سيناء ضرورة ملحة لجذب الكثافة السكانية

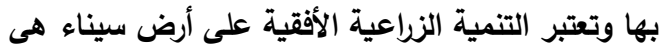

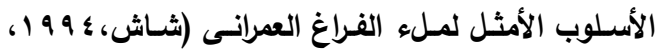

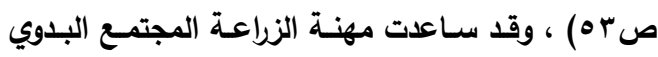

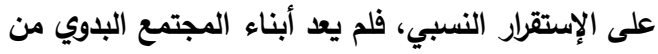

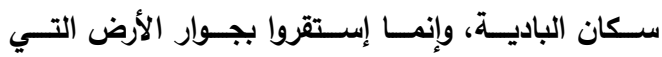

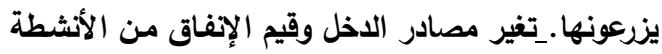
التقليدية كالرعي والصيد إلى العمل بالزراعة، والحصول على عائد نقدي في أوقات منتظمة عند حصد المحصول، وترتب على العائد النقدي، تفير مستويات الإنفاق وإرتفاع

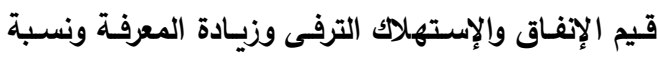
التعلم، وزيـادة المعرفة التكنولوجية، وخاصة في الأجيال

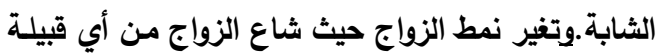

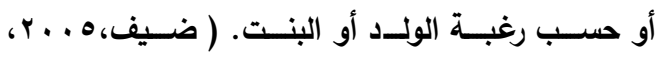
ص ص r

ويعيش البدو علي حياة الصيد سواء صيد الطيور

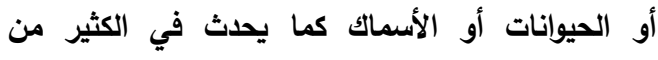
المناطق والغايات التي تعيش علي قنص الاسيمات الحيوان

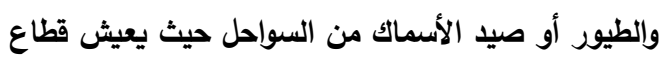

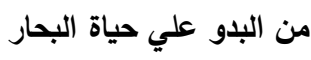
ونظرا للاعتبارات التاريخية القديمة التي تعكس الصيد كأحد الموارد الاقتصادية التي يعيش عليها قطاع كبير

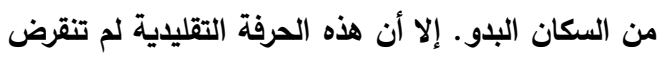

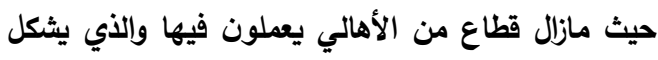

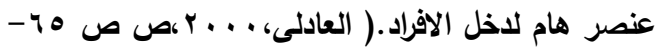

( 79

وكنلك تعتبر مهنة السياحة عامل مساعد للمزج والإتصال الثقافى، والحضارى الأى يساعد على صياغة الأنه الثخصية الإنسانية وتقليل المسافات الاجتماعية بين

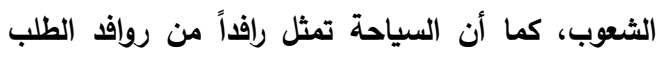
على طاقات وقدرات العمل فى فنون التثييد، والعمارة،

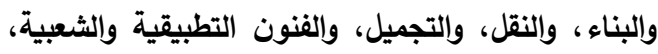


- ما مؤشرات الحراك الاجتماعى والمهنى فى المجتمع

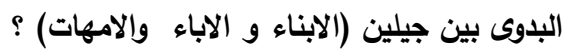

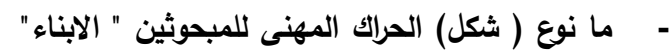

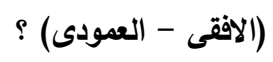

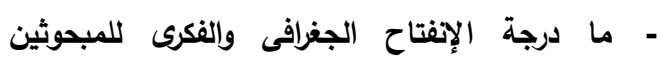

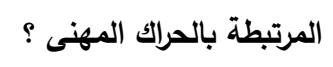

- ما الدوافع الاجتماعية للحراك المهنى للمبحوثين

$$
\text { بالمجتمعات البدوبة ؟ }
$$

- ما الدوافع الاقتصادية للحرايك المهنى للمبحوثين بالمجتمعات البدوية ؟

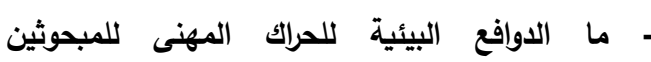

$$
\text { بالمجتمعات البدوية ؟ }
$$

\section{وتمثلت اهداف الدراسة فيما يلى :}

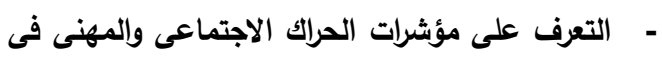
المجتمع البدوى بين جيلين (الابناء والاباء والامهات)

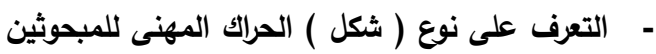

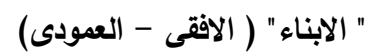

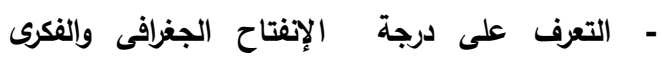

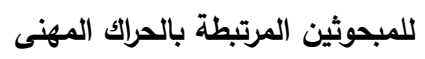

- التعرف على الدوافع الاجتماعية للحراك المهنى المثئي لمبحوثين

- التعرف على الدوافع الاقتصادية للحرالك المهنى للمبحوثين

- التعرف على الدوافع البيئية للحراك المهنى للمبحوثين

مفاهيم الاراسة

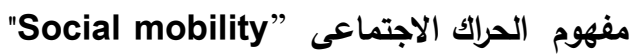
هو نوعٌ من التغيّر الذي يمَس الوضعية المراتبية

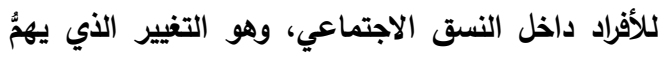

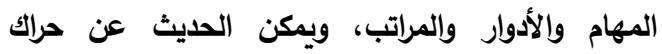
اجتماعي في اللحظة التي يتمكن فيها الفرد من تغيير الموقع الاجتماعي الأصلي، بالاتتقال إلى موقع اجتماعي لتهي

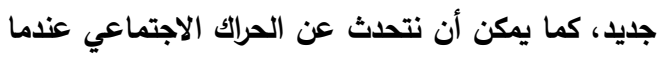

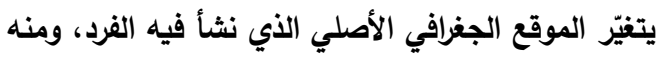

ايجاد بيئة محفزة للعمل تتيح للمواطن تنمية قدراتة واستعداداتة وتكون فيه الفرص على اساس القدرات وإلمواهب والجها الذاتى للحصول على مكانة وظيفية

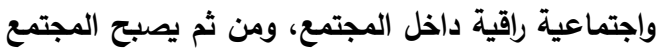

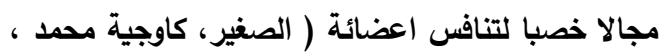
$\cdot(r+) \varepsilon$ وهناك مَيْل لاى بعضِ دارسي الحِرَاكَ الاجتماعي إلى

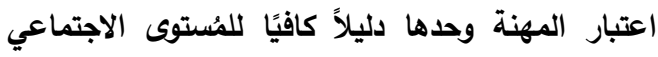

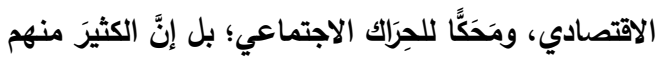

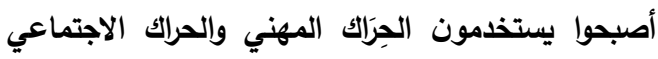
بنفس المعنى. (رابط الموضوع: https://www.alukah.net/fatawa_counsels/0/ 14371/\#ixzz5mwoySuVu) وتعد منطقة جنوب سيناء من المناطق التي تثهر تفيرات إجتماعية وثقافية لقاطنيها نتيجة ممارستهم العمل بالعديد من المهن ومنها الزراعة والسياحة، خاصة بعد ان تعرضت المجتمعات الصحراوية الى تغيرات

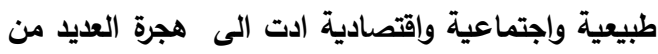
ابنائها (البدو) العمل بالحرف التقليدية مثل الرعى،

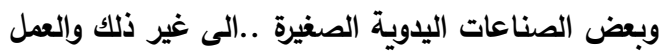
بمهن اخرى مستحدثة على المجتمع القبلى مثل العمل بقطاع السياحة - العمل الحر - اللالتحاق بالوظائف

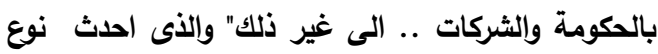

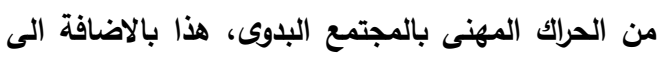

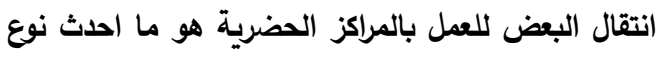

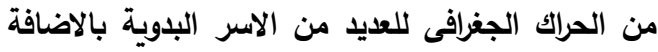
الى أن مهنة السياحة ساعدت على اكتساب مهارات

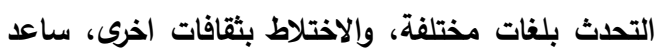
ذلك على احداث حراك ثقافى،بالاضافة الى انه كان هناك العديد من الدوفع الاجتماعية والاقتصادية والبيئية ساعدت على احداث تلك التحولات فى المجتمع البدوى وفى ضوء ما تقدم، تتحدد مشكلة الدراسة فى محاولاتها الاجابة على التسأولات التالية : 
التعريف الاجرائى لمفهوم الحراك المهنى

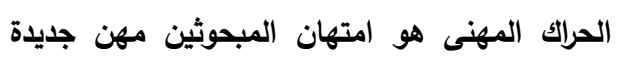

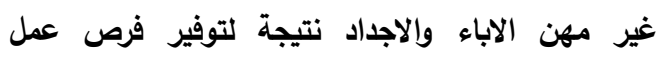

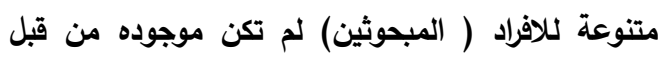

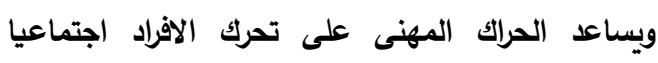

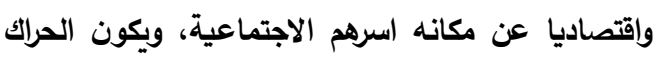

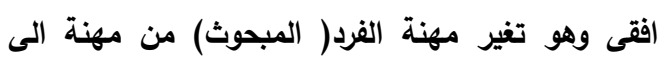

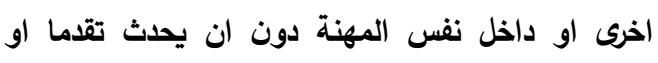

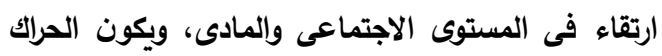

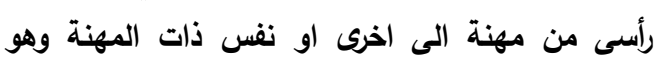

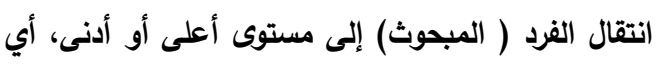

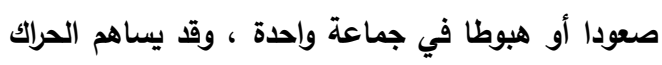

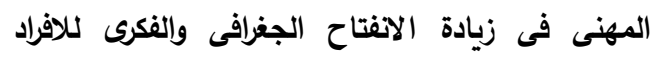

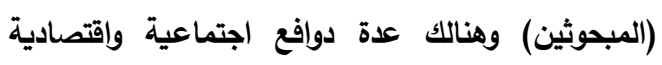

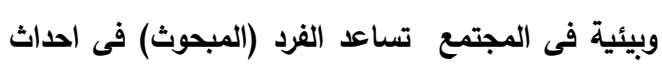
الحراك المهنى

$$
\text { الاجراءات البحثية }
$$

تعتبر هذه الدراسة من الاراسات الوصفية واعتمدت

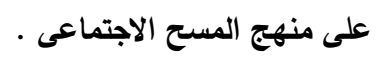

$$
\text { المجال الجغرافى والبشرى للاراسة }
$$

اجريـت الدراسـة فـى محافظـة جنـوب سـيناء روالتـى

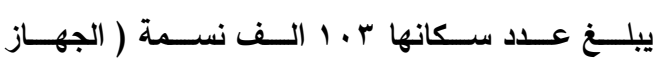

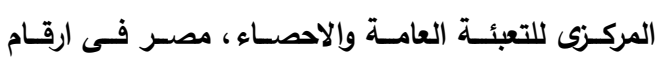

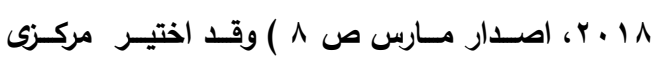

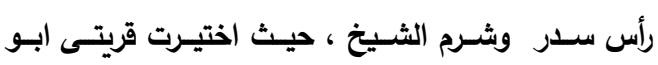

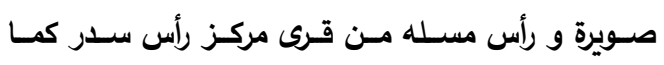

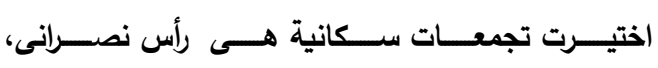

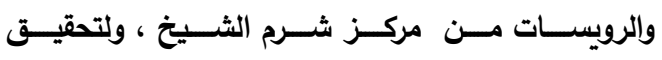

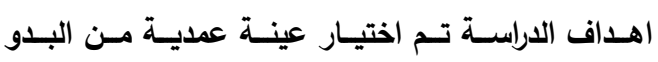

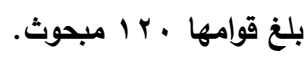

ينشأ التمييز بين حراك عمودي يهم التراتب، وآخر أفقي يهم حركات الهجرة أساسًا. http://www.roayapedia.org/wiki/index.php ويثير البعض الى أن مفهوم الحراك الاجتماعى

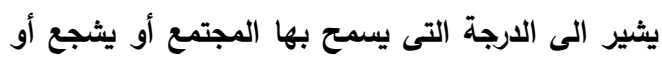

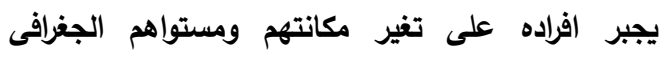

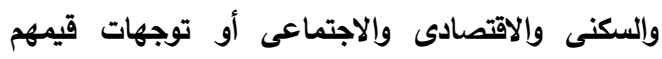

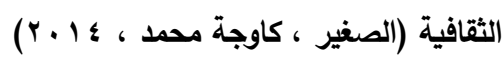

$$
\text { التعريف الاجرائى لمفهوم الحراك الاجتماعى }
$$

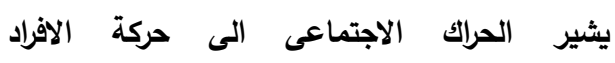
(المبحوثين) للانتقال الى طبقات مختلفة وجماعات مهنية , ومستوى ثقافى مختلف مستفيدين من فرص العمل

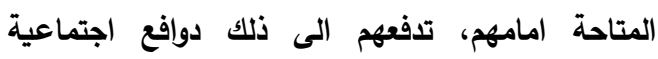
واقتصادية وبيئية فى المجتمع ويكون الحراك افقى، وهو

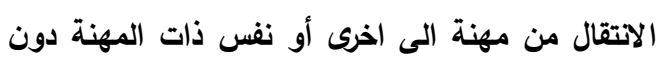

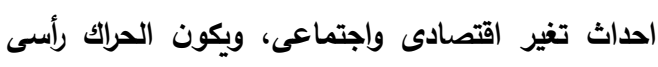

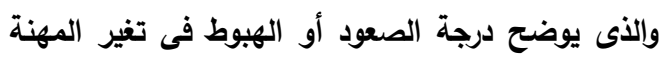
او ذات المهنة بإحداث تغير اقتصادى واجتماعى للافراد.

مفهوم الحراك المهنى "Occupational Mobility" الحراك المهنى ويقصد به تغير الفرد مهنة أسرته ، العهي

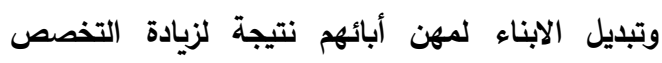

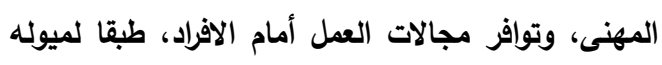

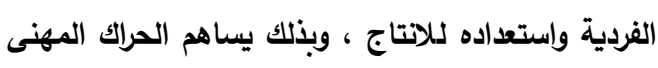

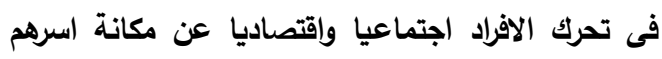

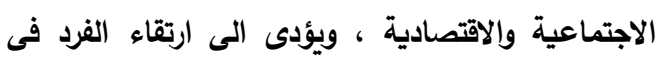

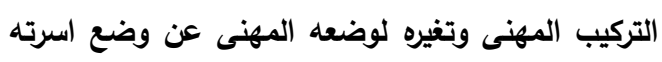
وصعودة اوهبوطه فى السلم المهنى، ربما الى تغيره مكان

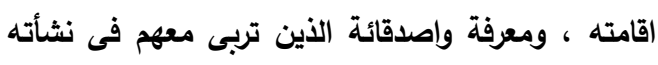

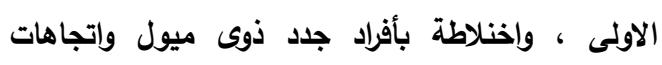

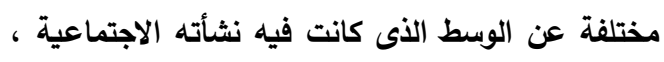

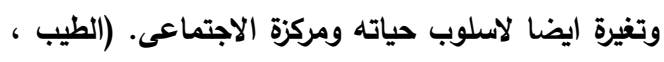

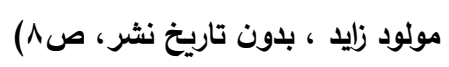




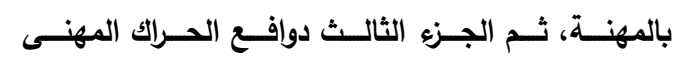

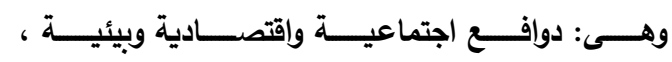

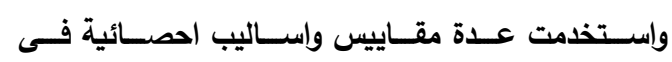
تحليـل البيانـات شـملت : (التكرارات - النسـب المئويـة

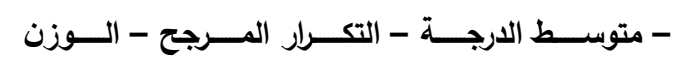

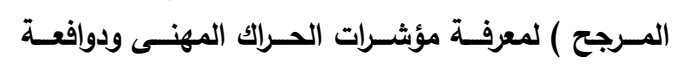

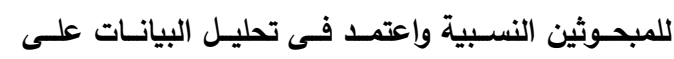
برنامج التحليل الاحصائى (SPSS)

\section{قياس المتغيرات البحثية}

اولا : أ- مؤشرات الحراك الاجتماعى بين الجيلين

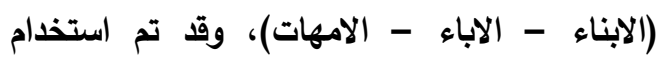
اسلوب القياس الموضعى لقياس الحراك الاجتماعى ولاء

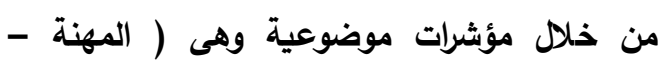

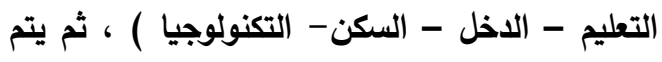

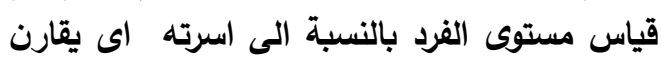
وضع الابن ووضع الاب.

1-مؤشر المهنة : ويقصد به نوع المهنة التى يقوم بها المبحوث وكذلك والد المبحوث وقته الاستبيان

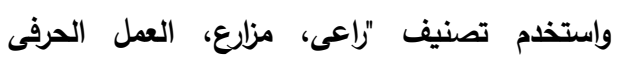

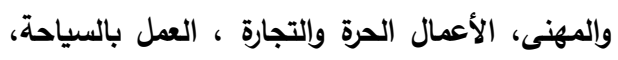

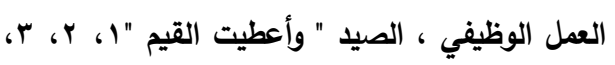

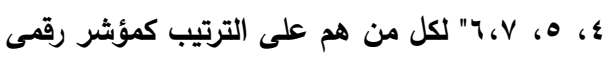

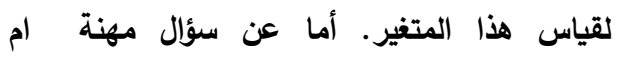

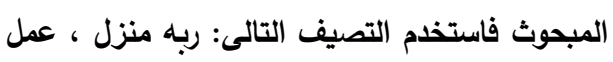

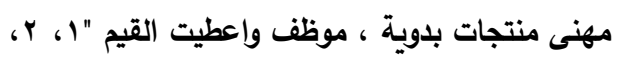

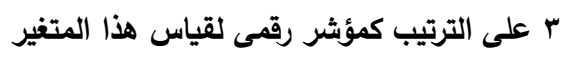

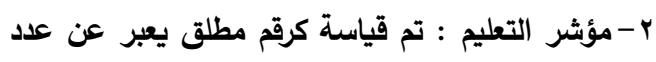
سنوات التعليم التى قضاها كل من المبحوث ورالد

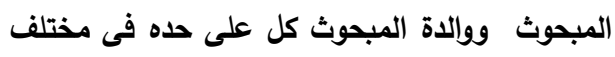
مراحل التعليم الرسمى. r-مؤشر الاخل : وتم قياسة كرقم مطلق يعبر عن النمان اجمالى المبالغ النقدية التى يتحصل عليها شهريا كل

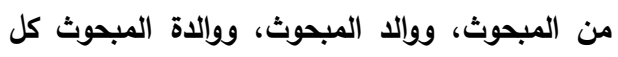
على حده كنظير للعمل الذى يقوم به . .
عينة الاراسة :

نظرا لتــوع المهن فـ العصر الحديث فـى المجتمـع

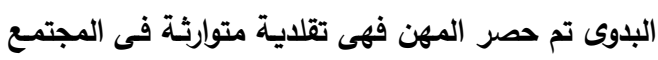

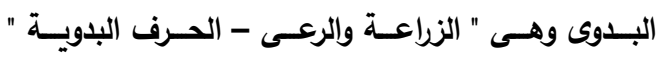

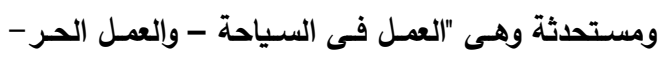
المهنى - الوظائف" لذا تم اختيار قرى وتجمعات مركزى فئي

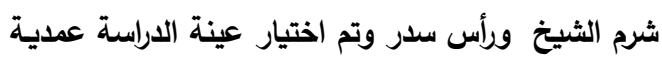

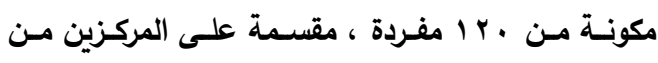

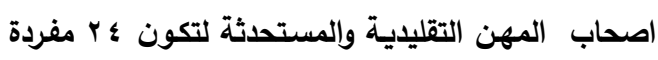
لكل مهنة يمتهنها المبحوثين .وتم اختيار العينة عمدية ولية

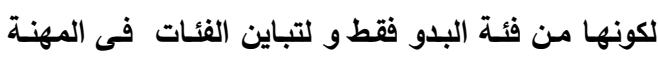

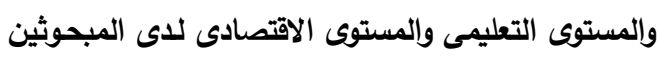

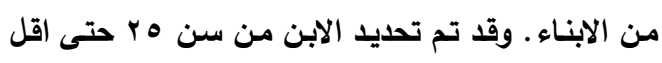

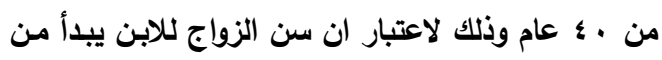

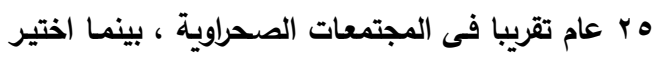

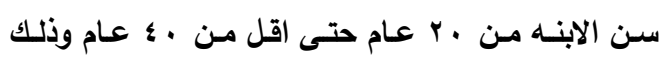

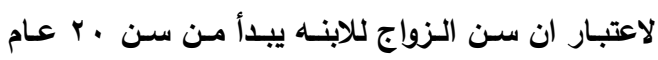

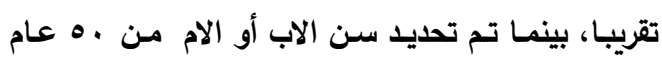
فأكثر.

\section{جمع وتحليل بيانات الدراسة}

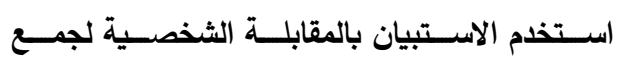

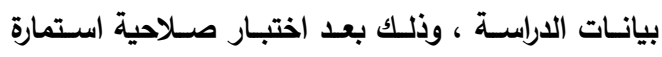

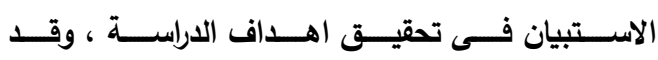

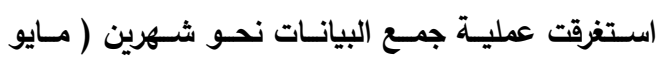

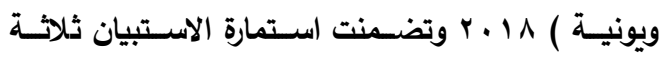

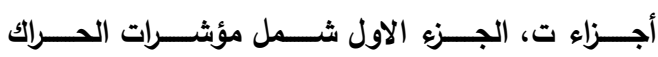

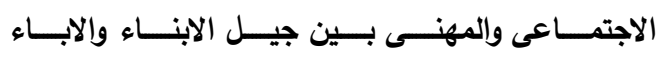

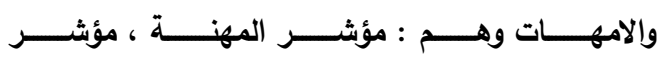

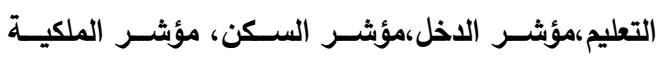

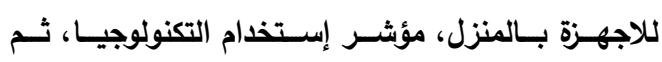

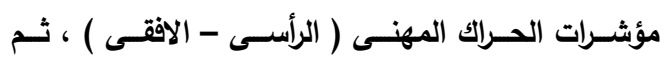

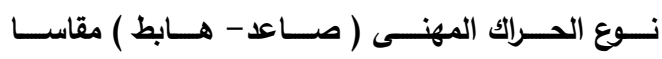

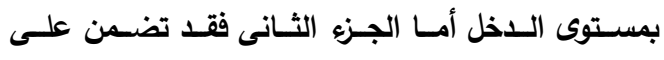

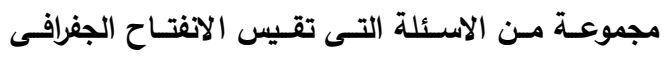

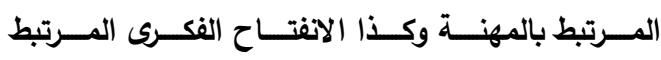




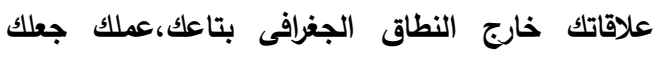

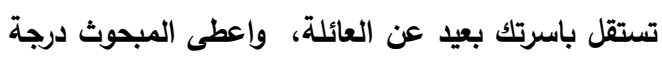

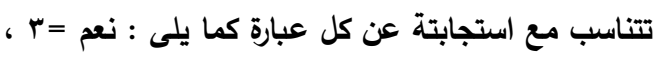

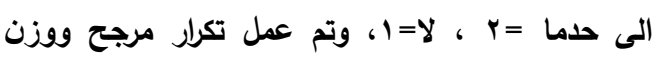

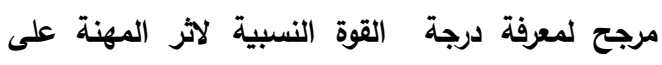
الحراك الجغرافى r - درجة الانفتاح الثقافى حيث تم قياسة من خلال إستيفاء رأى المبحوث فى الافتاح الثقافي

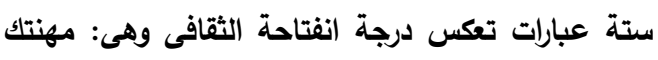

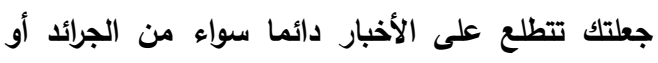
التليفزيون أو الأتترنت، بتتفرج على الاخبار دائا لقواء عن الجزات الفضائية

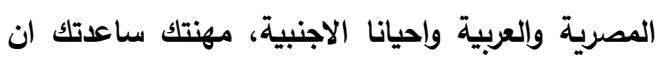

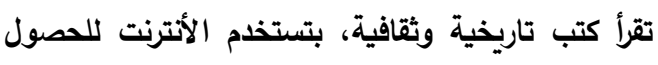
على المعلومات والمعرفة التى تفيدنى فى عملى، تصني، عملك

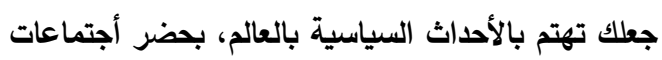
واشارك المحليات احيانا بحكم عملى، وتم منح المبحوث

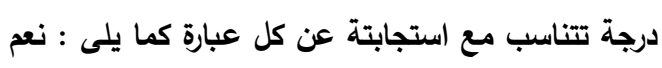

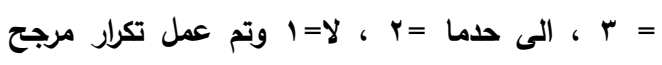

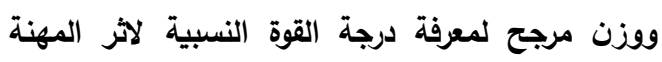

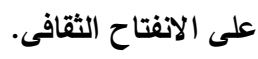

ثالثا : دوافع الحراك المهنى فى المجتمع البدوى

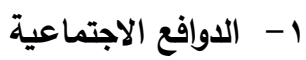
أ: لقد تم تناول الدوافع المرتبطة (التعليم - المكانة الاجتماعية) حيث تم قياسها من خلال إستيفاء رأي الماتي

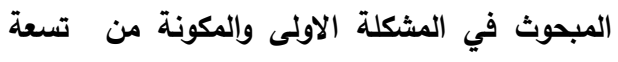

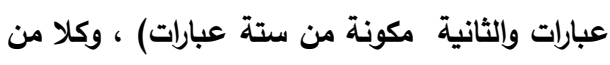

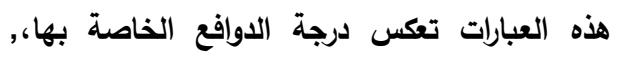

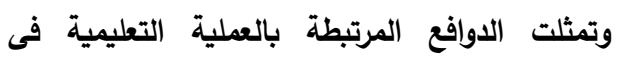

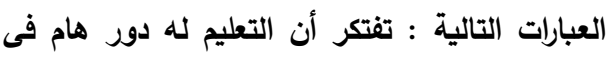

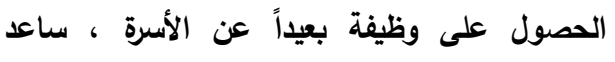

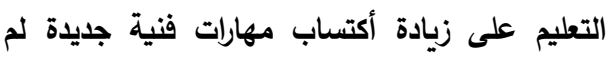

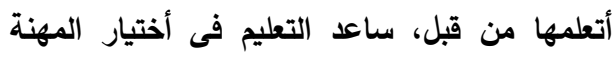

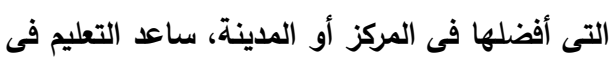

צ- مؤشر السكن: ويقصد مستوى السكن وخدماته للمبحوث ووالد المبحوث كلا على حدة وهو مقياس مكون من اربع عبارت (مناسبة المسكن لعدد افراد

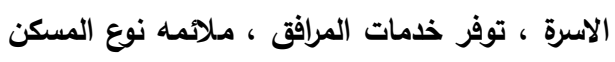

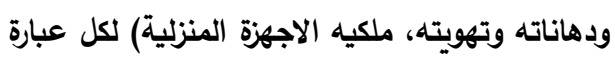

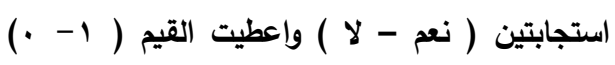
كمؤشر رقمى لقياس هذا المتغير ه - إستخدام التكنولوجيا : ويقصد به لهاسئ مستوى استخدام

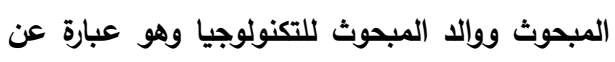

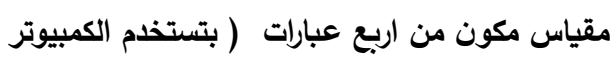

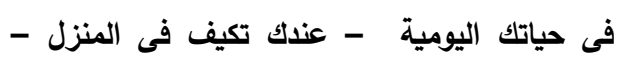

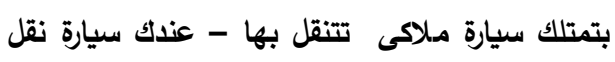
بتستخدما فى شغلك او تقضى بها حياتك ) " لكل عبارة استجابتين ( نعم - لا ) واعطيت القيم ( · كمؤشر رقمى لقياس هذا المتغير ( لعم اعطيت ب- نوع الحراك المهنى للابناء

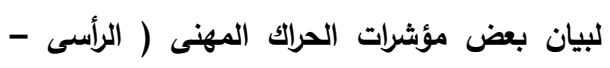

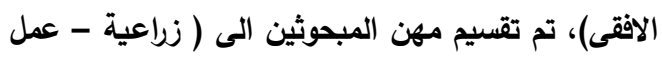

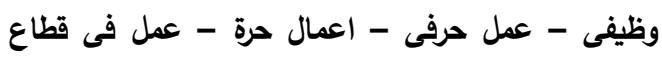
السياحة) لتوضيح نسب كل مؤشر من المؤشرات السابقة

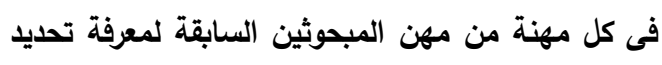

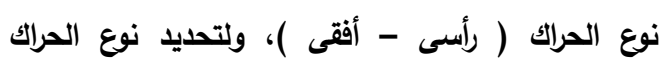

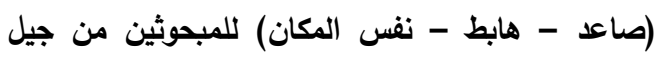

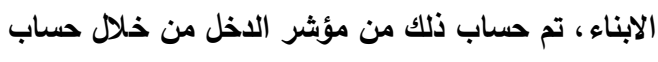

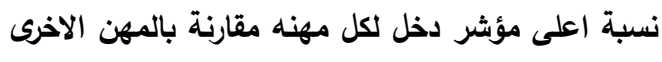

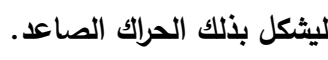

ثانيا : الانفتاح الثقافى والجغرافى المرتبط بالمهنة 1- درجة الاففتاح الجغرافى

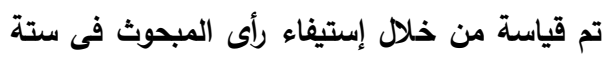

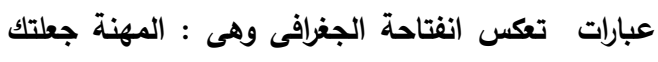

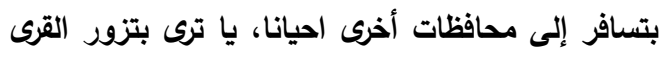

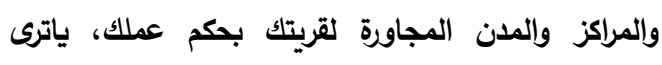

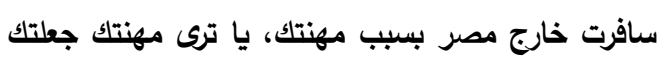

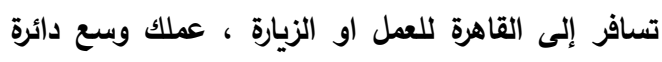




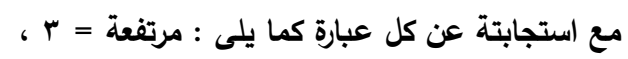

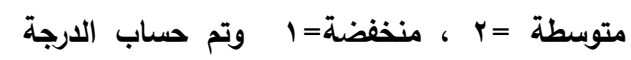
المتوسطة لكل عبارة

ج: لقد تم تناول الدوافع المرتبطة بالبيئة حيث تم قياسه

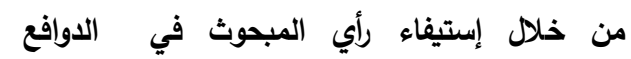
والمكونة من خمسة عبارات) ، وكلا من هذه العبارات

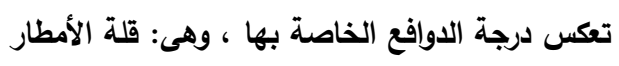

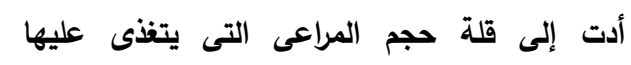

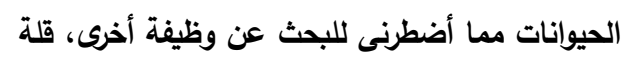

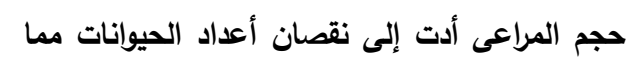

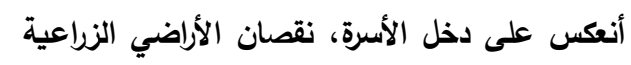
بسبب تحويلها إلى أراضي سكنية وسياحية،تدهور

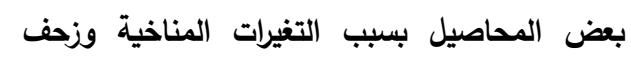

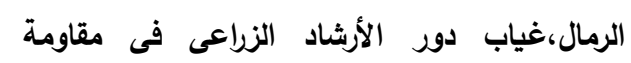

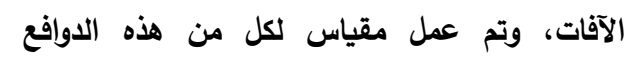

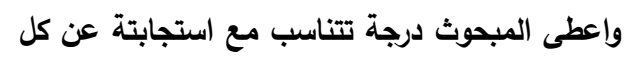

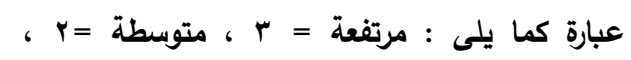

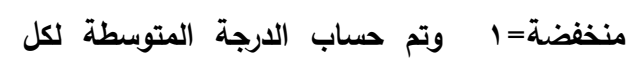

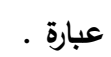

د: لقد تم تناول الدوافع الاقتصادية حيث تم قياسه من

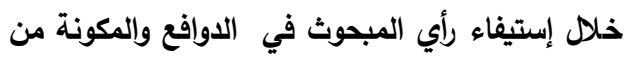

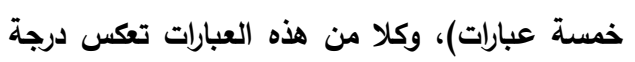

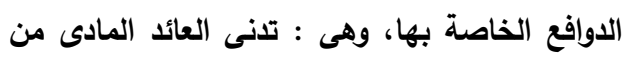

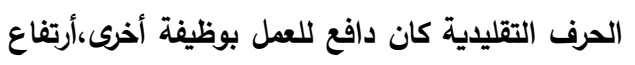

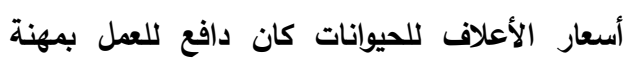
أخرى، الرغبة فى تحسن مستوى الاخل من العمل بمهن غير تقليدية، الرغبة فى تحسن مستوى الدخل

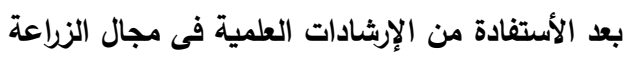

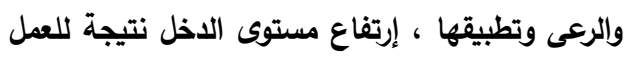

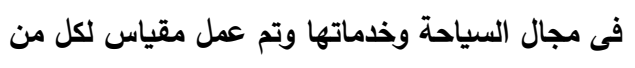

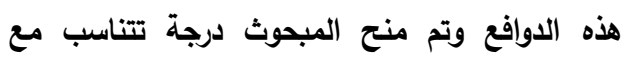

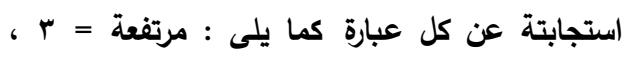

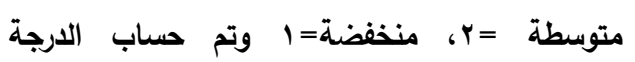
المتوسطة لكل عبارة
تحقيق طموحى والعمل فى مجال تخصصى، لاى رغبة فى العمل فى المدن والإقامة بها، ساعد التعليم

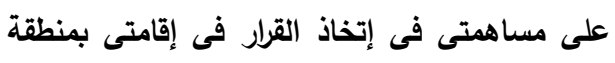

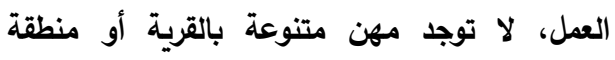

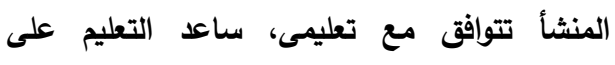

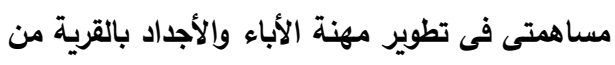

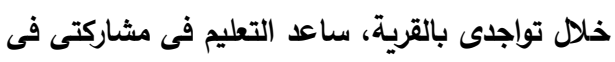

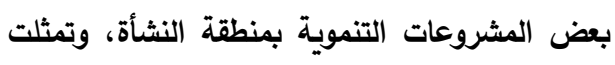
الدوافع المرتبطة بالمكانة الاجتماعية فى العبارات

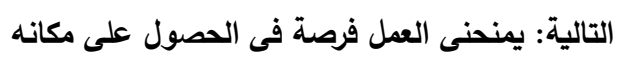

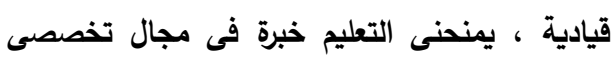

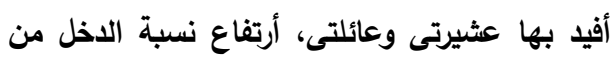
العمل تضع للفرد مكانة داخل قبيلته، السلطة وأتخاذ القرار للشخص مرتبط بالسن الاكبر فقط،مكانة الثخص وهيبته الإجتماعية مرتبطة بمكانة قبيلته وعمله، يساعد العمل على إكتساب مهارات معرفية تزيد من مكانته الثخصية والإجتماعية. وتم عمل مقياس لكل من هذه الدوافع وتم منح

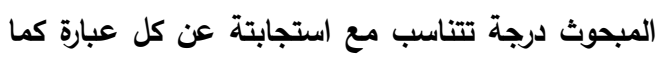

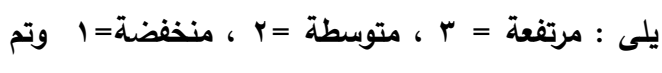
حساب الدرجة المتوسطة لكل عبارة ب: لقد تم تناول الدوافع المرتبطة بإستخدام التكنولوجيا

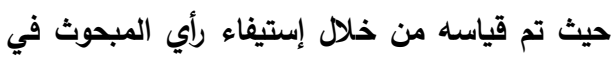

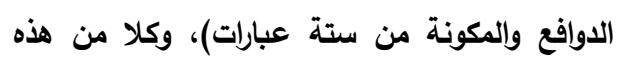

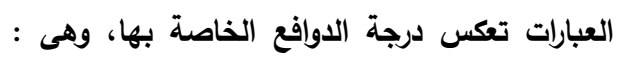

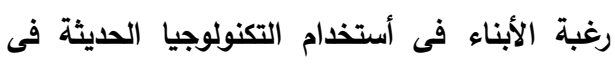

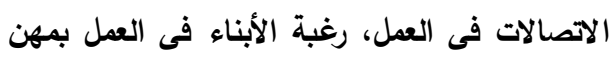

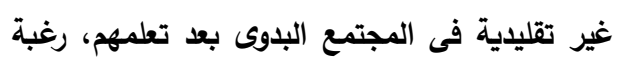

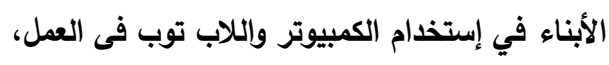
الرغبة فى إمتلاك وأستخدام أجهزة تكنولوجية حديثة

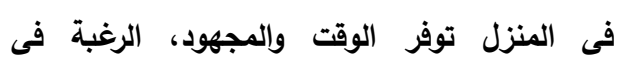

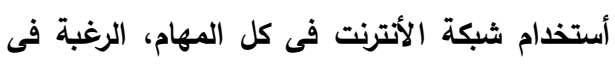

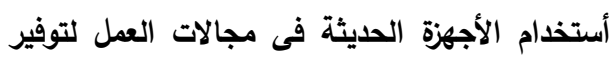

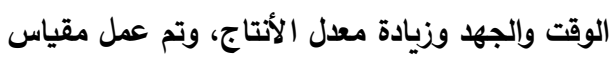
لكل من هذه الدوافع وتم منح المبحوث درجة تتناسب 
9 \% \% للعمل فى مهنة الحرف والمنتجات اليدوية، وهو

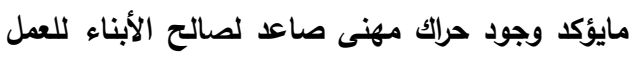

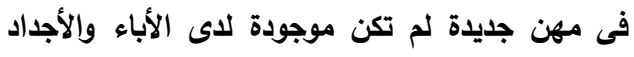
وهجر الأبناء المهن التقليلية للأباء والأجداد.

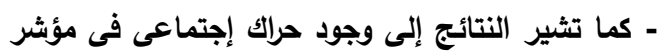

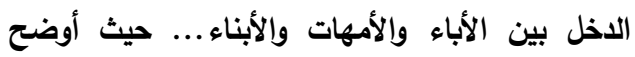

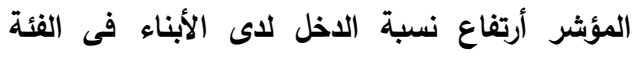

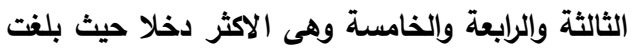

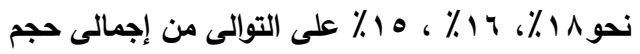

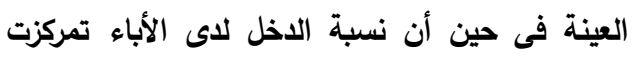

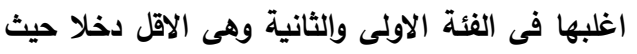
بلغت نحو 32\% ، 53\% اغلبه الأى الاباء بينما تمركزت

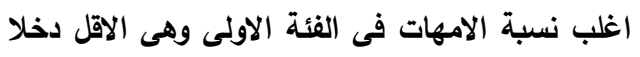

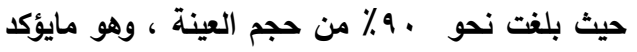

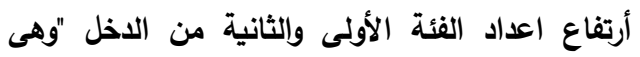

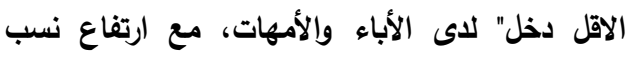

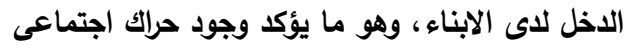
صاعد فى مؤشر الدخل لصالح الابناء.

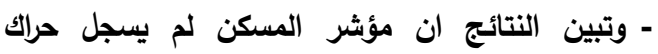

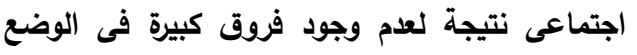

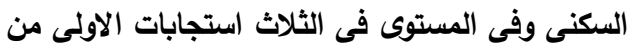
المسكن، وقد سجلت الاستجابة الرابعة من المسكن

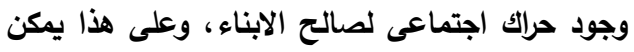

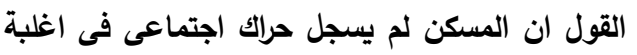

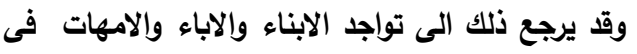
منزل واحد او منازل متقاربة فى نفس المكان وقد

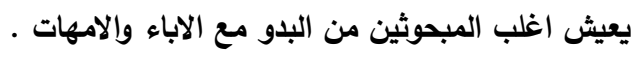

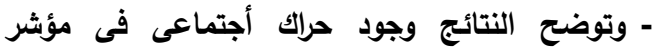

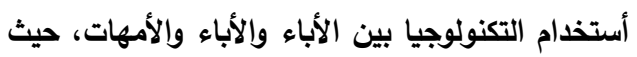
أرتفعت نسبة مستخدمى الكمبيوتر لاى الأبناء، وبلغت

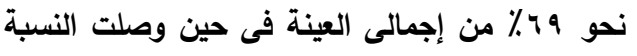

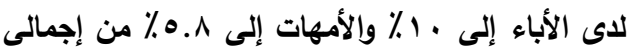
حجم العينة، وبلغت نسبة أستخدام التكييف لاى الأبناء

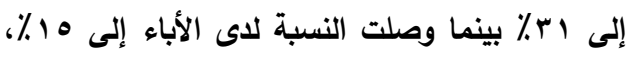

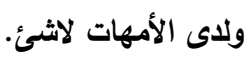

نتائجج الدراسة

فيما يلى عرض ومناقثة اهم النتائج التى توصلت لالته

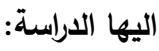

اولا : مؤشرات الحراك الاجتماعى والمهنى بين

$$
\text { الجيلين (الابناء - الاباء - الامهات ) }
$$

وتثير النتائج الواردة بجدول رقم (1) وجود حراك

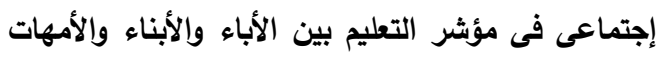
. . حيث أوضحت الداسة أن نسبة المؤهلات العلياء

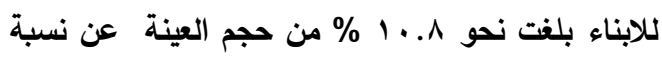

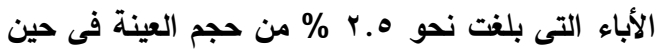

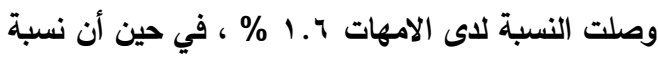
الحاصلين على شهادة متوسطة من الأبناء وصلت إلى

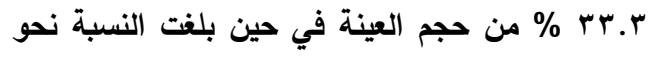

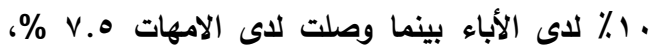

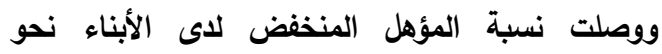

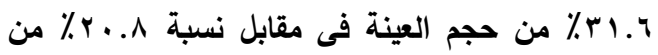

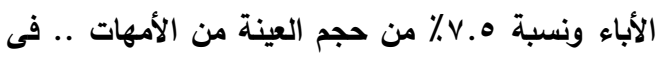

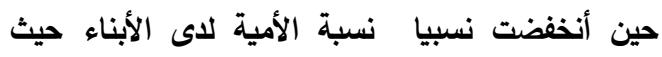

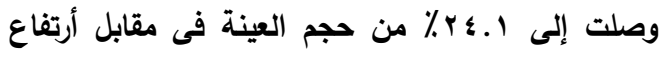

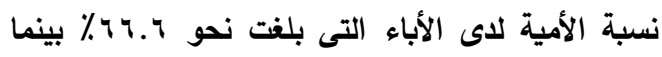

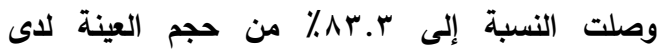
الأمهات، وهو مايدل على وجود حراك إجتماعى صاعد لمؤشر التعليم لصالح الأبناء عن الأباء والأمهات. والتهات - كما تبين النتائج وجود حرالك إجتماعى فى مؤشر الأباء

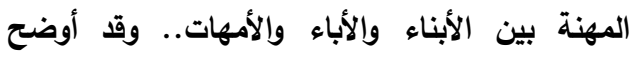
المؤشر أرتفاع نسبة الأبناء للعمل فى القطاعات التاءلية الألياء

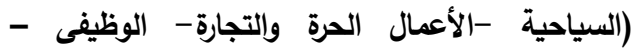

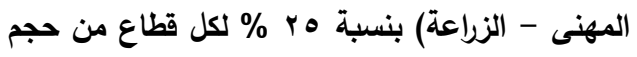

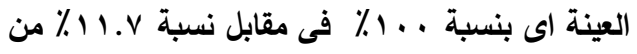

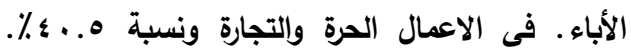

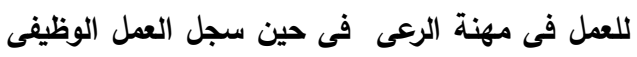

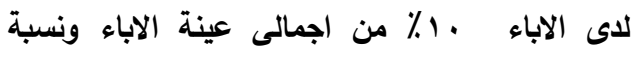

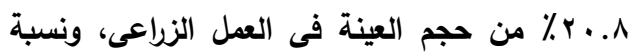

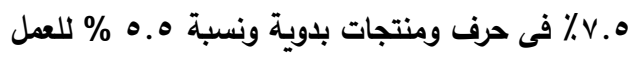

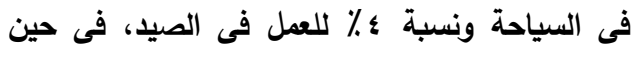

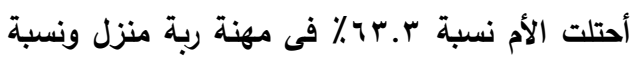


Menoufia J. Agric. Economic \& Social Sci. Vol. 4 October (2019): 2 iv - rq

جدول رقم ( ) : التوزيع العددى والنسبى لبعض مؤشرات الحراثك الإجتماعى عبر الجيلين

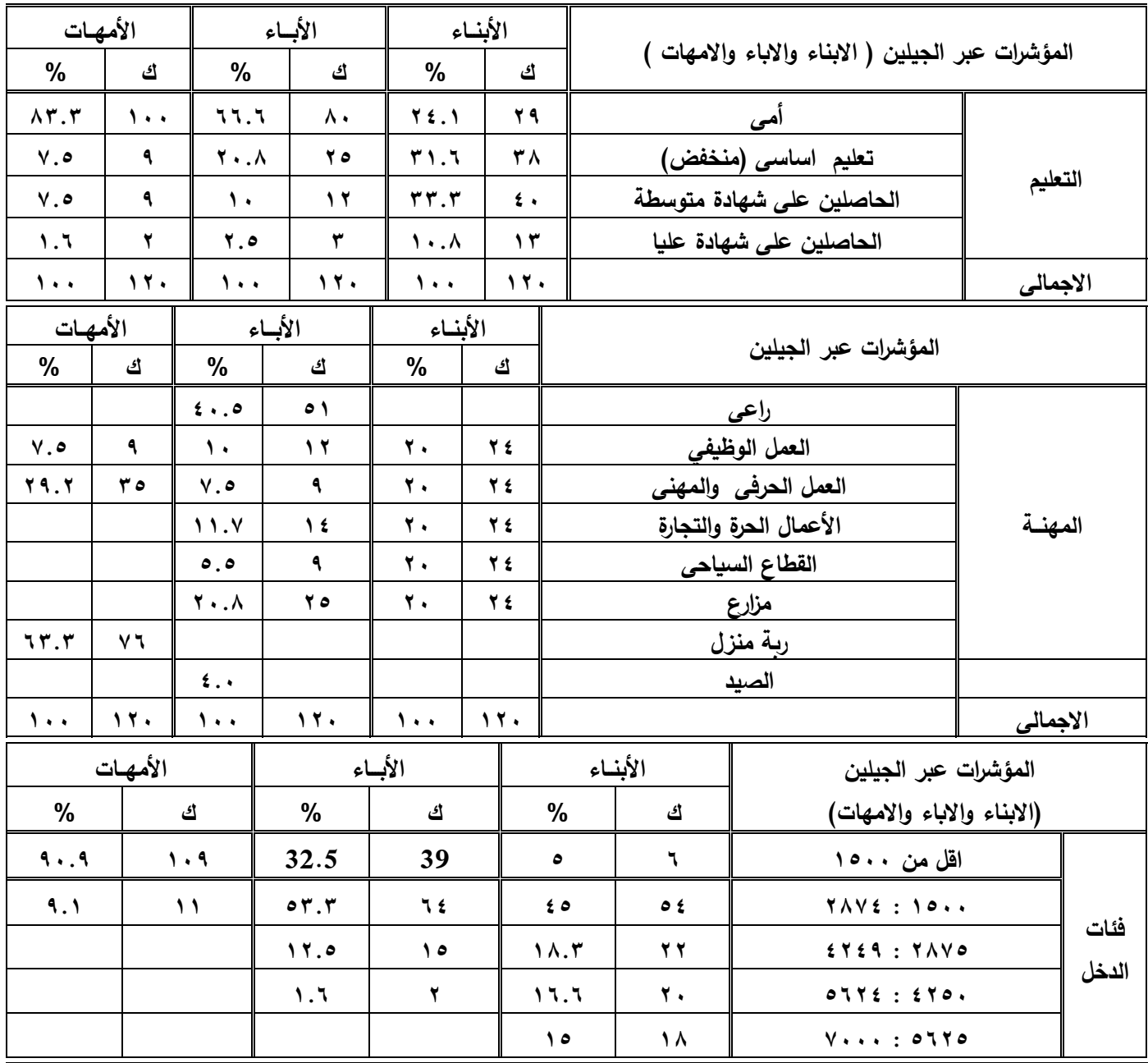

\begin{tabular}{|c|c|c|c|c|c|c|c|}
\hline \multicolumn{2}{|c|}{ الأمهات } & \multicolumn{2}{|c|}{ الأبـاء } & \multicolumn{2}{|c|}{ 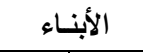 } & \multirow{2}{*}{\multicolumn{2}{|c|}{ المؤشرات عبر الجيلين }} \\
\hline$\%$ & ك & $\%$ & ك & $\%$ & ك & & \\
\hline$\Delta \wedge$ & $v$. & $\leqslant r$ & 01 & 07 & $\$ 1$ & مناسبة المسكن لعدد أفراد الأسرة & \\
\hline$\leq 0$ & 0 \& & r & $\varepsilon$. & r & $\leq 4$ & توفر خدمات المرافق بالمسكن & \\
\hline Tr & V4 & $\Delta$ & 79 & $\Delta \wedge$ & $v$. & ملاثمة نوع المسكن ودهاناتة وتهويته & المتحن \\
\hline- & - & $\varepsilon r$ & or & 71 & Ar & ملكية أغلب الأجهزة المنزلية & \\
\hline
\end{tabular}

\begin{tabular}{|c|c|c|c|c|c|c|c|}
\hline \multicolumn{2}{|c|}{ الأمهات } & \multicolumn{2}{|c|}{ الأبـاء } & \multicolumn{2}{|c|}{ الأبنـاء } & \multirow{2}{*}{\multicolumn{2}{|c|}{ المؤشرات عبر الجيلين }} \\
\hline$\%$ & ك & $\%$ & ك & $\%$ & S & & \\
\hline 0.1 & $\mathrm{v}$ & 1. & ir & 79 & AT & كمبيوتر أو لاب توب & \\
\hline- & - & 10 & 11 & I & rs & تكييف & \\
\hline- & - & $\varepsilon$ & 0 & rV & rr & سيارة ملاكى & 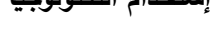 \\
\hline- & - & rr & rq & 60 & 72 & سيارة نقل & \\
\hline
\end{tabular}

المصدر: جمت وحسبت من بيانات الاراسة الميدانية بأستذام الحاسب الالى 
إجمالى عينة العمل الحر،وبلفت لاى مهنة الوظيفة

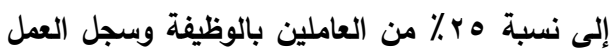
الزراعى نسبة ·r٪ من إجمالى عينة العاملين

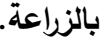
- وصلت نسبة العاملين من المؤهلات تعليم مخفض

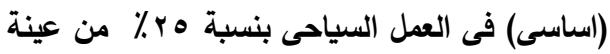
مهنة السياحة فى حين سجل العمل الحر نسبة r.r.o من إجمالى العينة فى حين بلفت فى العمل الوظيفي نسبة 9 ٪\%.من العاملين فى الوظيفة.

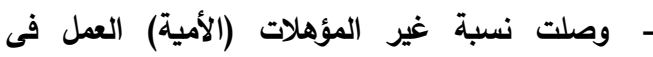
القطاع الزراعى نحو 0 ؛ ٪ من إجمالى العينة بقطاع الزراعة، بينما بلغت نسبة المؤهلات التعليمة المنخفضة نحو r.r.r\% من عينة مهنة الزراعة وهو مايثير إلى حدوث حراك مهنى راسي لاى الحاصلين

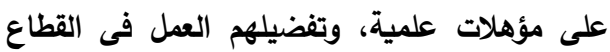
السياحى والأعمال الحرة عن مهنة الأجداد والأباء.

r ب النسبة لمؤشر الاخل:

أ: أن نسبة الفئة الثانية من الاخل "المنخفض "

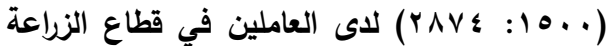

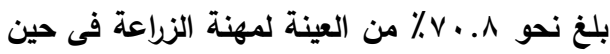

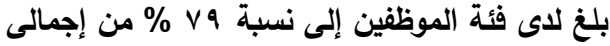

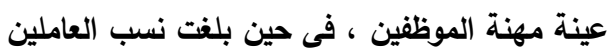

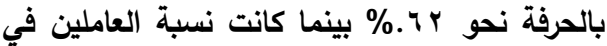

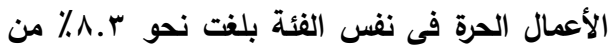
عينة مهنة الاعمال الحرة، و ؛ ٪ من مهنة العياحة وهو مايوضح أرتفاع اعداد نسبة المزارعين والموظفين والحرفين من هذه الفئة الأقل دخلاً.

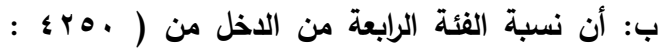

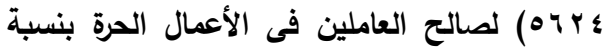

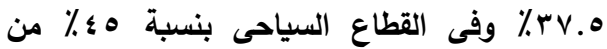
إجمالى العينة بينما لم تسجل ايى نسبة من العاملين فى القطاع الزراعى وفى الوظائف وفى العمل الحرفى فى هذه الفئة من الاخل.

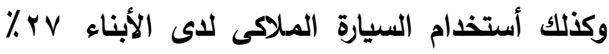

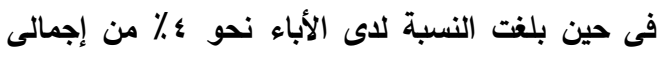
حجم العينة، وبلفت نسبة أستخدام السيارة النقل لاى الى الى العين

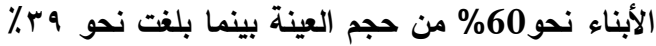
لاى الأباء - وقد يرجع ذلك للأستفادة منها فى نقل متطلباتهم الحياتية. ويعتبر العامل التكنولوجى ذات تأثير كبير فى إحاث التهاث التغير الاجتماعي، فتقدم المواصلات، ووسائل الإتصال المختلفة، والآلات التكنولوجية كل ذلك أدى إلى حدوث تغيرات فى أساليب العمل، والإنتاج، وعلاقات العمل، والعلاقات الاجتماعية، وأنماط السلوك، والتفاعل وأساليب

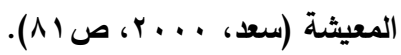
ويعتبر تايلور من أوائل علماء الأتثروبولوجيا الاجتماعية الذين أرجعوا التفير الاجتماعي إلى التى التكنولوجيا حيث يرى أن السبب الرئيسى للتطور الثقافى الإيه يتمثل فى تطور الفنون الصناعية ونموها كما يؤكد العالم أوجبرون على أهمية الثقافة المادية بما تثمله من

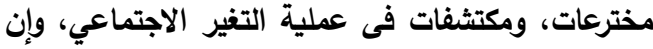
كان لا ينكر وجود عوامل أخرى تؤدى إلى ظاهرة التغير كعوامل البيئة، وإلعوامل الطبيعية، والعوامل البيولوجية، غير أن العامل التكنولوجى يسهم إسهاماً فعالاً فى إحداث

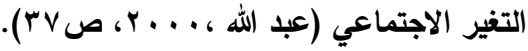
ثانيا : نوع الحراك المهنى للابناء - توضح النتائج الواردة بجدول رقم (ץ) مايلي: 1: النسبة لمؤشر التعليم:

- بلغت نسبة العاملين الحاصلين على مؤهل عالى فى لـ العمل السياحى هـ \% من عينة العاملين فى السياحة

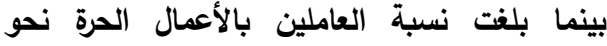

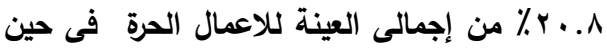
بلفت نسبة العاملين فى الوظيفة إلى نحو r.^٪.

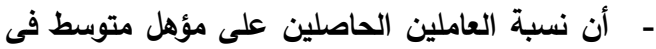
العمل السياحى بلغت ـ\% من عينة العاملين فى لهى

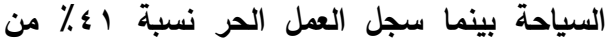
جدول رقم (ץ): التوزيع العددى والنسبى لبعض المؤشرات الحراك المهنى 


\section{A. A. Refae}

\begin{tabular}{|c|c|c|c|c|c|c|c|c|c|c|c|}
\hline \multicolumn{2}{|c|}{ السياحى } & \multicolumn{2}{|c|}{ الأعمال الحرة } & \multicolumn{2}{|c|}{ العمل الحرفى } & \multicolumn{2}{|c|}{ العمل الوظيفي } & \multicolumn{2}{|c|}{ مزارع } & \multirow{2}{*}{\multicolumn{2}{|c|}{ المؤشرات }} \\
\hline$\%$ & ك & $\%$ & s & $\%$ & s & $\%$ & ك & $\%$ & ك & & \\
\hline ro & 9 & $r \cdot . \wedge$ & ○ & . & . & $\Lambda . r$ & r & . & . & شهادة عليا لحلى & \\
\hline 0. & Ir & \&1 & 1. & rq & $v$ & ro & 1 & $r \cdot . \Lambda$ & • & شهادة متوسطة & التعليم \\
\hline ro & 9 & rv.o & 9 & rr.r & $\wedge$ & rq & $v$ & rr.r & $\wedge$ & تعليم اساسى & \\
\hline . & . & . & . & rv.o & 9 & rv.o & 9 & $\leq 0$ & 11 & امى & \\
\hline · & · & - & $\cdot$ & $\Lambda . r$ & r & $\Lambda . r$ & r & $\Lambda . r$ & r & اقل من . 10 & \\
\hline$\{.1$ & 1 & A.r & $r$ & Tr.o & 10 & $\vee 9.1$ & 19 & $\vee \cdot . \wedge$ & iv & YAVE : $10 \ldots$ & \\
\hline Ir.o & $r$ & 17.7 & $\varepsilon$ & rq.1 & $v$ & ir.o & $r$ & $r \cdot . \Lambda$ & ○ & $\varepsilon r \leqslant q: r \wedge \vee 0$ & الاخل \\
\hline$\varepsilon 0.1$ & 11 & rv.o & 9 & . & . & . & . & . & . & OTY\&: : \& Y . & \\
\hline rv.o & 9 & rv.o & 9 & . & . & . & . & . & . & V...: : orro & \\
\hline 7. & 10 & $7 \varepsilon$ & 17 & \& & 11 & 7. & 10 & « & 11 & مناسبة المسكن & \\
\hline$\leqslant 1$ & 1. & $\{1$ & 1. & r.r & $\wedge$ & \&1 & 1. & rr.r & $\wedge$ & توافر خدمات & المسكن \\
\hline $7 \varepsilon$ & 17 & 7. & 10 & $\varepsilon \wedge$ & ir & or & ir & O^.r & $1 \varepsilon$ & نوع المسكن & \\
\hline$\Lambda \varepsilon$ & $r_{1}$ & A. & $r$. & 7. & 10 & 7. & 10 & « & 11 & ملكية الأجهزة & \\
\hline Av.० & 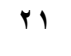 & 91.7 & rr & 52 & 13 & 72 & 18 & rv.o & 9 & كمبيوتر & \\
\hline$\leqslant 0$ & 11 & $\varepsilon \wedge$ & ir & ri & $v$ & ro & 9 & $\Lambda . r$ & r & تكييف & استخدام \\
\hline rr.r & $\wedge$ & $\varepsilon \wedge$ & ir & 20 & 5 & rq & $v$ & $\{.1$ & 1 & سيارة ملاكى & التكنولوجيا \\
\hline 72 & 18 & 80 & 20 & 52 & 13 & 37.5 & 9 & 52 & 13 & سيارة نقل او جيب & \\
\hline
\end{tabular}

أ: بلغت نسبة مناسبة المسكن لعدد افراد الاسرة لاى مهنة المزارعين ؟ ؟ ٪ من عينة المزارعين بينما

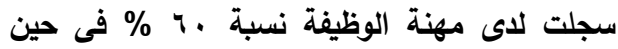
وصلت الى نسبة ؛ ؛ \% من عينة الحرفيين بينما

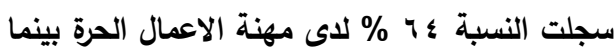
بلفت النسبة ـ ـ ٪ لاى العاملين فى مهنة السياحة،

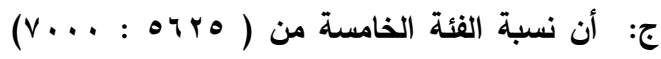

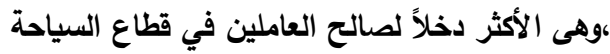

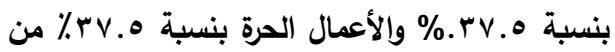

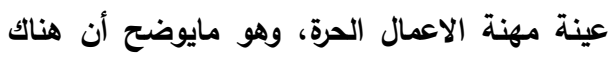

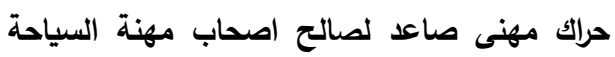
والاعمال الحرة.

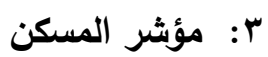


ويتضــح ان الأحسداث التـى أثـرت علـى الســياحة

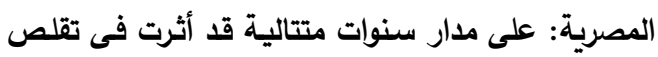

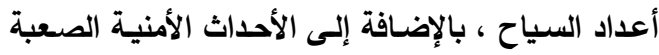

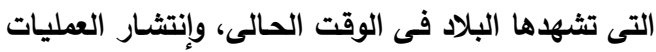

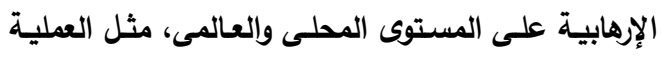

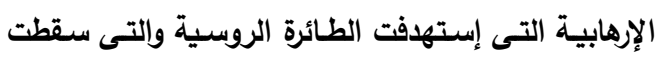
فى وسط سيناء عقب إقلاعها من مطار شرم الثيخ بفترة

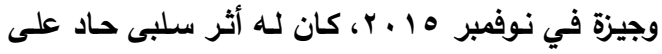
العملية السياحية، وعلى الإقتصاد القومى للبلاد، ومازالت

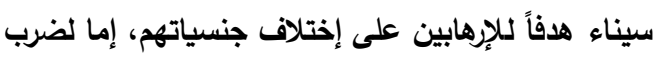

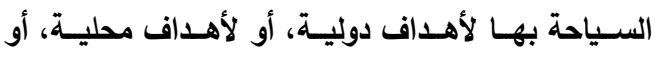

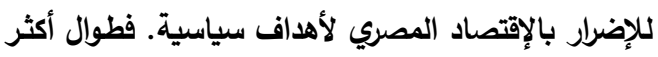
مـن إثنى عشـر عامـاً تعرضت سيناء لهجمـات إرهابيـة

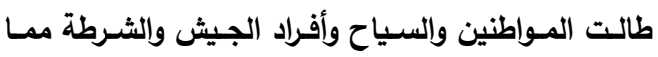

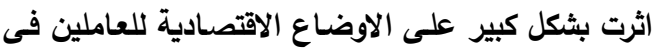
هذا القطاع من البدو فـى هذه الاونــة ويتضـح ذلك من الأن مستوى الاخل الذى كان يفوق ذلك فى الاعوام الماضية

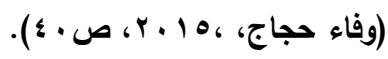

ثالثا: الحراك المهنى بين جيل الابنـاء مقاسـا

$$
\text { بمستوى الاخل: }
$$

توضح النتائج الواردة بجدول رقم (ץ) المهن الاكثر حراكا فى المجتمع البدوى ، ومنها يتبين وجود حرالك

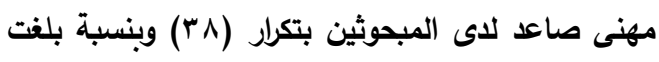

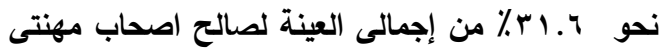
السياحة والاعمال الحرة كما يشير الجدول إلى علىم وجود حراك مهنى هابط لاى المبحوثين (الابناء)، فى الاعمال

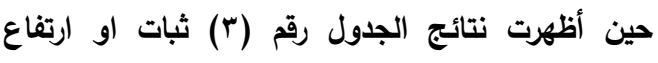
طفيف للحراك المهنى لاى بعض المبحوثين، وبنسبة

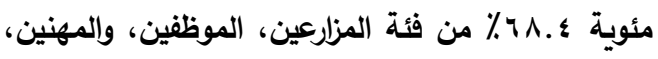
بالمقارنة بالمهن الاخرى ( السياحة والاعمال الحرة )

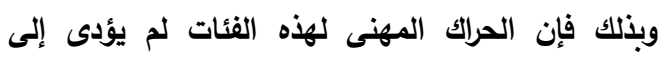
إحداث تغير طبقى لديهم.
ويوضح ذلك تحسن مستوى السكن للعاملين بقطاع

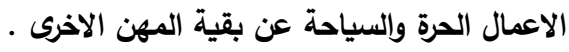
ب: إن نسبة توافر خدمات المرافق بالمسكن لاى

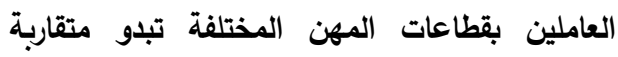

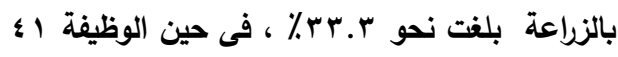

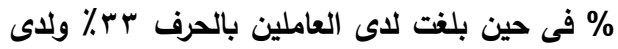

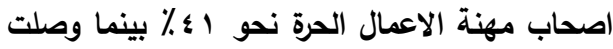

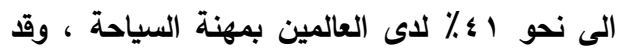

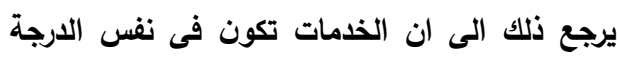

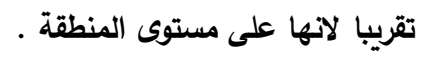
ج: ويوضح مؤشر السكن ان ملكية اجهزة منزلية بالمسكن اكثر لصالح فئات العاملين بقطاعى الاعمال

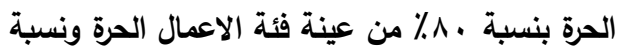

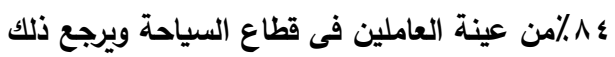
لارتفاع نسب الاخل لايهم

ع : مؤشر استخدام التكنولوجيا

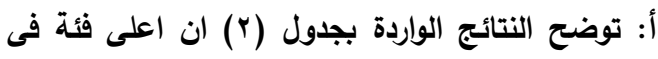
استخدام الكمبيوتر العاملين فى قطاع الاعمال الحرة حيث بلغت نحو 9 \% ثم تلى ذلك العاملين بالسياحة

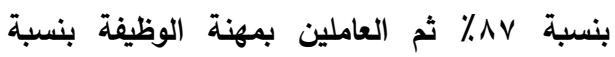

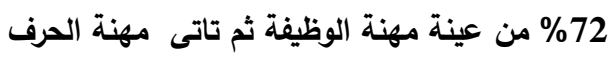

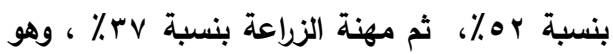
ما يثير الى وجود حراك مهنى صاعد لصالح فئة الاعمال الحرة والسياحة. ب: وعلى هذا الاساس يوضح نتائج الجدول رقم ( ب )

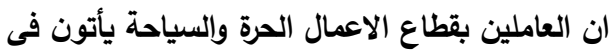

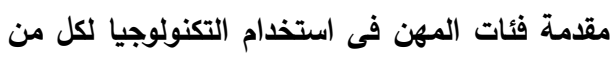

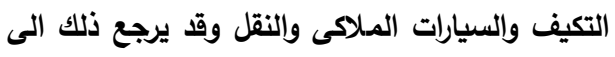

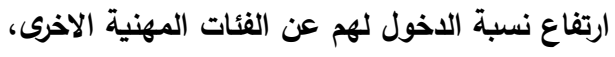
وهو ما يثير الى وجود حرالك مهنى صاعد لصالح اصحاب مهنتى السياحة والاعمال الحرة . 
جدول رقم (ץ): التوزيع العددى والنسبى لنوع الحراك المهنى لجيل الأبناء مقاسا بمستوى الاخل

\begin{tabular}{|c|c|c|}
\hline النسبة & العدد & حراك مهنى \\
\hline$r 1.7$ & rᄉ & 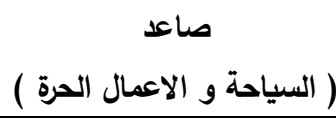 \\
\hline- & - & هابط \\
\hline$\Im \wedge . \varepsilon$ & Ar & 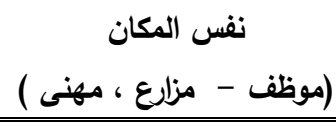 \\
\hline$\%$ & ir. & المجموع \\
\hline
\end{tabular}

المصدر: جمعت وحسبت من بيانات الدراسة الميدانية بأستخدام الحاسب الالى

ووزن مرجح ץ ؟ .. ،وهو مايوضح مدى أنتمائهر وحب

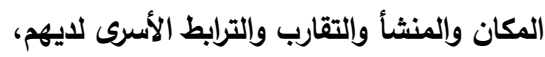

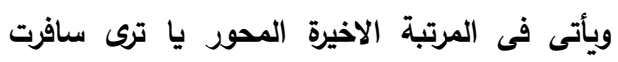

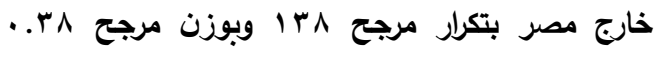
وهوما يوضح مدى تمسكهم وحبهم وانتمائهم الى وطنهم وأهليهم والمكان الذى نشئوا فيه.

خامسا: أثر الحراك المهنى على درجة الانفتاح الثقافى

توضح نتائج بيانات الجدول رقم ( • ) ان تنوع المهن لها دور هام وفعال فى درجة الانفتاح الثقافى بقوة

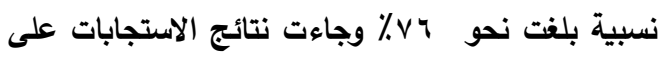

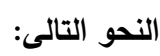

حيث تبين بيانات المحاور الستة للانفتاح الثقافى بالجدول رقم (ه) ، ان المحور مشاهدة القنوات الفضائية

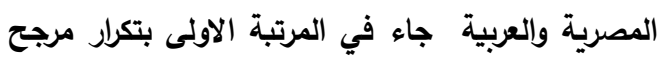

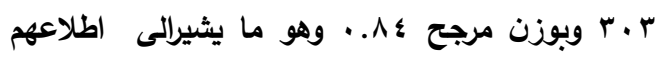
على الثقافة الام المصرية وإلعببة واحيانا الاجنبية والاخذ

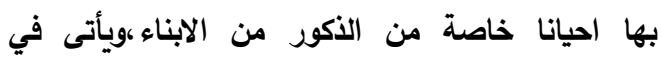

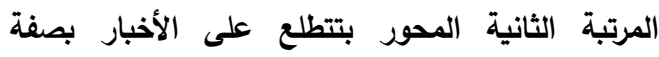
مستمرة سواء من الجرائد أو التليفزيون أو الأنترنت

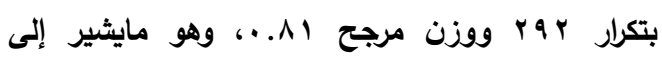
أنفتاح البدو على العالم الداخلى وإلخارجى، ثم يأتى في
رابعا: الحراك المهنى و درجة الانفتاح الجغرافى لدى المبحوثين يتضح من النتائج الواردة بجدول رقم ( ؛ ) ان تنوع

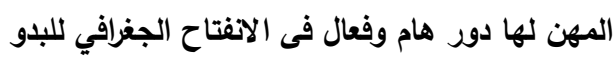

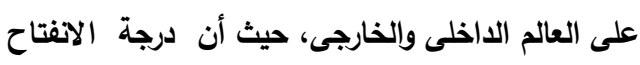

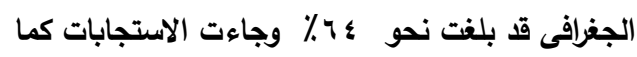
يلى: حيث تثير بيانات المحاور الستة للانفتاح الحغرافى

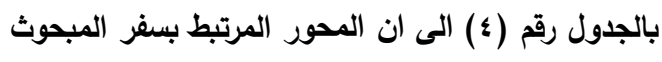

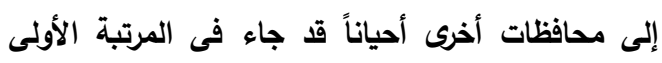

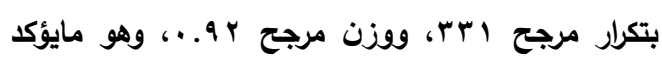
أنفتاح البدو على باقى المحافظات بعد إلتحاقه بعمله ونه

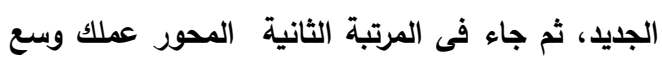
دائرة علاقاتك خارج النطاق الجغرافى بتاعك بتكرار مرجح

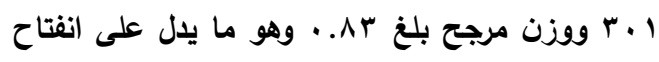

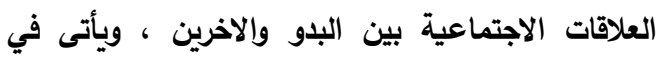

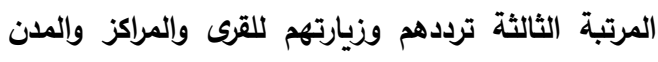

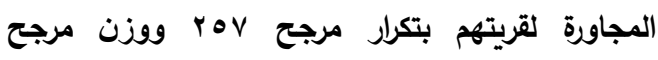
ا.V... وهو مايشير إلى أنفتاحهم على القرى والمراكز

$$
\text { المجاورة والتعاون معها والتقارب منها. }
$$

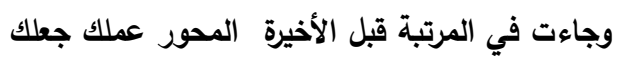
تستقل باسرتك بعيد عن العائلة بتكرار مرجح 111 


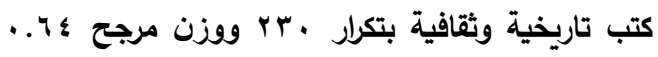

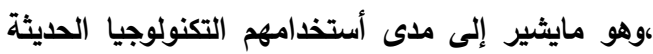
في الحصول على المعلومات والمعرفة وإن قل ذلك في الكي

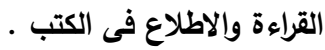

المرتبة الثالثة المحور أهتمام البدو بالأحداث العياسية

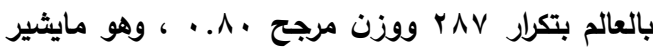
إلى مدى تغير أهتماماتهم وتطلعهم بالأحاث العالمية

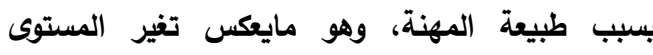
الثقافى لديهم، و يأتى في المرتبة السادسة المحور بتقرأ

جدول رقم ( ) : درجة المتوسط المرجح والاوزان المرجحة لدور الحرالك المهنى على الانفتاح الجغرافى.

\begin{tabular}{|c|c|c|c|c|c|c|c|}
\hline 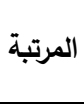 & مرجح & 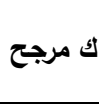 & ע & إلى حا & نعم & البيـان & م \\
\hline 1 & 0.92 & 331 & 4 & 21 & 95 & المهنة جعلتك بتسافر إلى محافظات أخرى احيانا & 1 \\
\hline r & 0.71 & 257 & 19 & 65 & 36 & $\begin{array}{c}\text { يا ترى بتزور القرى والمراكز والمدن المجاورة } \\
\text { لقريتك بكم عملك }\end{array}$ & r \\
\hline$\bullet$ & 0.38 & 138 & 111 & - & 9 & ياترى سافرت خارج مصر بسبب مهنتك & $r$ \\
\hline$\varepsilon$ & 0.60 & 218 & 71 & - & 49 & يا ترى مهنتك جطتك تسافر إلى القاهرة للعمل او & $\varepsilon$ \\
\hline r & 0.83 & 301 & 19 & 21 & 80 & عملك وسع دائرة علاقاتك خارج النطاق الجغرافى & ๑ \\
\hline 0 & 0.42 & 168 & 103 & - & 17 & عملك جعلك تستقل باسرتك بعيد عن العائلة & 7 \\
\hline & 3.86 & 1413 & 380 & 107 & 286 & (0.64) - (0.6) مرجح & لأجه \\
\hline
\end{tabular}

المصدر: جمعت وحسبت من بيانات الدراسة الميدانية بأستخدام الحاسب الالى

جدول رقم (0): درجة المتوسط المرجح والاوزان المرجحة لاثر الحرالك المهنى على الأنفتاح الثقافى (الفكرى)

\begin{tabular}{|c|c|c|c|c|c|c|c|}
\hline 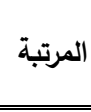 & مزجح & ك مرجح & $\gamma$ & إلى حـ & نعم & البيـان & b \\
\hline$r$ & 0.81 & 292 & 18 & 32 & 70 & 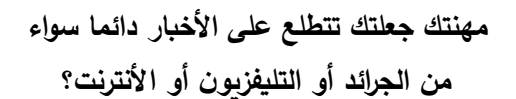 & 1 \\
\hline 1 & 0.84 & 303 & $\mathbf{0}$ & 57 & 63 & بتتفرج على القنوات الفضائية المصرية والعربية & $r$ \\
\hline 7 & 0.64 & 230 & 31 & 68 & 21 & مهنتك ساعدتك ان تقرأ كتب تاريخية وثقافية & $r$ \\
\hline$\varepsilon$ & 0.79 & 285 & 16 & 43 & 61 & 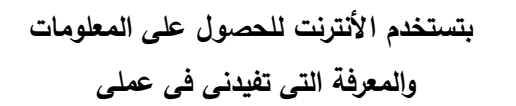 & $\varepsilon$ \\
\hline$r$ & 0.80 & 287 & 13 & 47 & 60 & عملك جعلك تهتم بالأحداث السياسية بالعالم & - \\
\hline 0 & 0.68 & 244 & 29 & 58 & 33 & بحضر أجتماعات واشارك المحليات احيانا بحكم & 7 \\
\hline & 4.56 & 1641 & 107 & 305 & 308 & \multicolumn{2}{|c|}{ لأجمالى س مرجح (0.76) } \\
\hline
\end{tabular}

المصدر: جمت وحسبت من بيانات الاراسة الميدانية بأستخدام الحاسب الالى 
وهو ما يشير الى مدى معرفتهم بان التعليم لله دور كبير

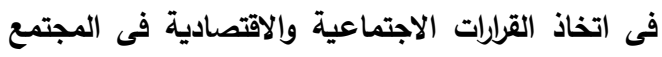

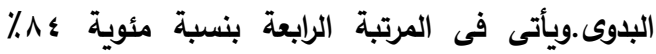

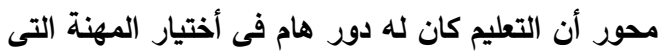

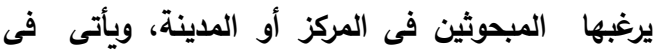
المرتبة الخامسة بنسبة مئوية .^٪ محور قدرة التعليم على تطوير مهنة الأباء والأجداد بالقرية خلال تواجدى لهائه بها. وهو ما يوضح ان الفئة المتعلمة اخذت بلواء العلم فى تطوير مهنة الاجداد مثل استخدامهم التكنولوجيا

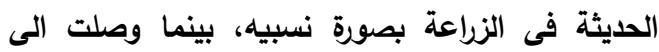

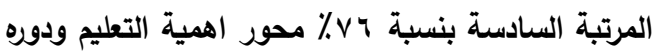
الهام فى الحصول على وظيفة بعيداً عن مكان النشأة،

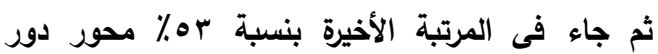
التعليم خلق الرغبة لاى فى العمل بالمدن والإقامة بها لهاتها

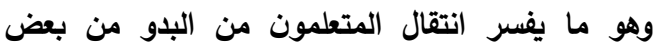

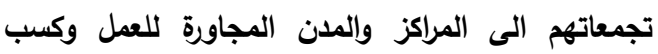

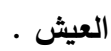

وبذلك يتضح دور التعليم الهام كدافع رئيسي للحراك

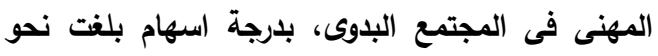

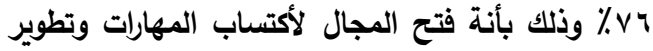

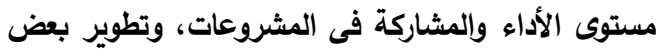

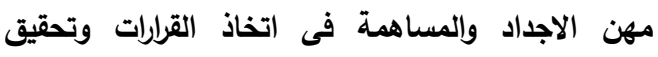
الرغبات الطموح المهنى فى المجالات التى يفضلها المبحوثين لتحقيق طموحاتهم.

\section{وتؤكد النظرية الوظيفية العلاقة الايجابية بين}

المستوى التعليمى للفرد وكل من مستوى الوظيفة والاخل

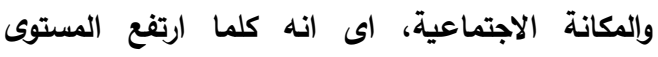

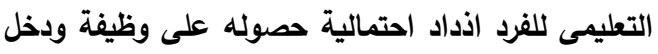
ومكانة اجتماعية أعلى وإنه وسيلة اساسية لحراك الفرد

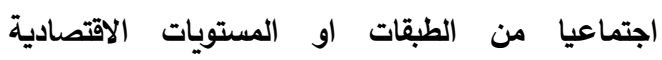

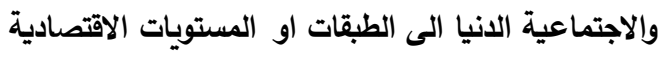

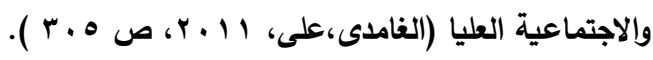

وبذلكك تعتبر الثقافة أحد العوامل الهامـة التى تتؤدى

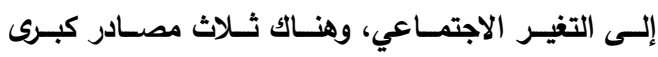
للعناصر الثقافية، وهى الإختراع والإتتشـار والإستعارة ،

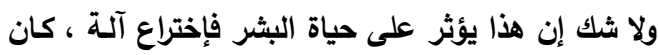

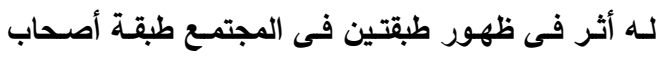

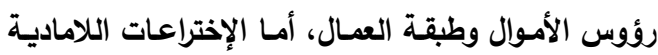
فهى مثل الكتابة، والضمان الاجتماعي، وحقوق الإنسان،

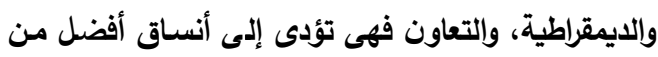

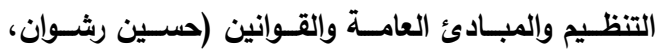

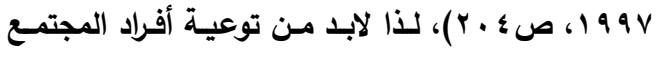

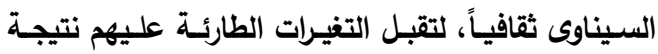

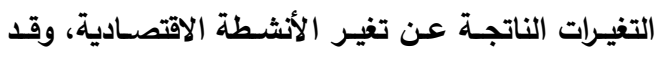

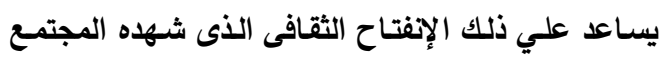
السـيناوى مـن خـلال التوســع فـى مؤسســات التعلـيم

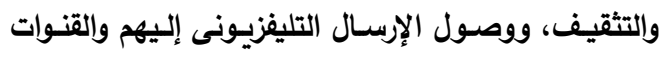

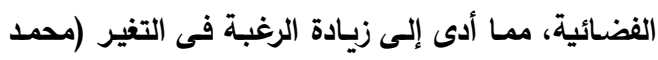

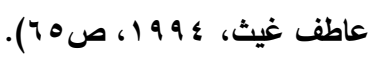
سادسا:الدوافع الاجتماعية للحراك المهنى بالمجتمع البدوى الدو 1- التعليم يبين جدول (†) المحاور التسعة لدافع التعليم فى الدى الحراك المهنى، وتثير بياناته الى ان محور التعليم له له دور هام فى الحصول على وظيفة بعيداً عن الأسرة، جاء

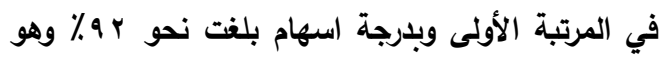

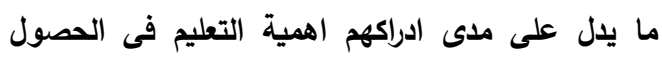

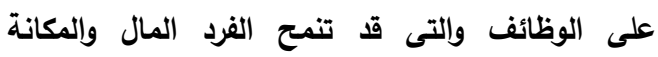

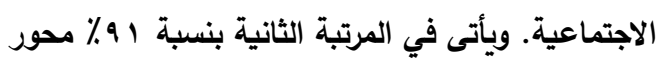
ساعد التعليم على زيادة أكتساب مهارات فنية جليدة لم

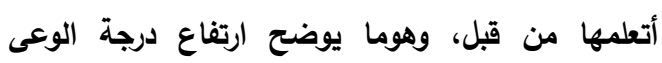

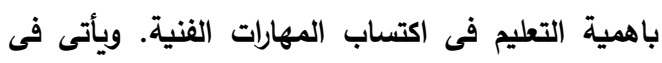

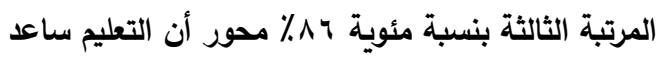
فى مساهمتى فى أتخاذ القرار فى أقامتى بمنطقة عملى. 
جدول رقم ( 7 ): المتوسطات الحسابية والاوزان النسبية لاففع التعليم .

\begin{tabular}{|c|c|c|c|c|}
\hline 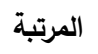 & $\%$ & متوسط الارجة & البيـان & b \\
\hline 1 & ar & r.V५ & تفتكر أن التعليم له دور هام فى الحصول على وظيفة بعيداً عن الأسرة. & 1 \\
\hline r & 91. & r.vo & ساعد التعليم على زيادة أكتساب مهارات فنية جديدة لم أتعلمها من قبل & r \\
\hline$\varepsilon$ & $\Lambda \varepsilon$ & r.or & ساعد التعليم فى أختيار المهنة التى أفضلها فى المركز أو المدينة & r \\
\hline$\wedge$ & $\checkmark$. & 1.1 & ساعد التعليم فى تحقيق طموحى والعمل فى مجال تخصصى & $\varepsilon$ \\
\hline 9 & or & 1.7 & لاى رغبة فى العمل فى المدن والإقامة بها & - \\
\hline$r$ & $\wedge 4$ & r.४. & ساعد التعليم على مساهمتى فى إتخاذ القرار فى إقامتى بمنطقة العمل & 9 \\
\hline 7 & vi & r.r. & لا توجد مهن متنوعة بالقرية أو منطقة المنشأ تتوافق مع تعليمى & $v$ \\
\hline 。 & A. & r.\& & سواجدى بالقرية على مساهمتى فى تطوير مهنة الأباء والأجداد بالقرية من خلال & $\wedge$ \\
\hline$v$ & ז4 & 1.9 & ساعد التعليم فى مشاركتى فى بعض المشروعات التنموية بمنطقة النثأة & 9 \\
\hline & จ..11 & r.rq & المتوسط العام & \\
\hline
\end{tabular}

المصدر: جمعت وحسبت من بيانات الاراسة الميدانية بأستخدام الحاسب الالى

والحكم فيها مما يساعد ذلك على رفع مكانتة بين قبيلتة.

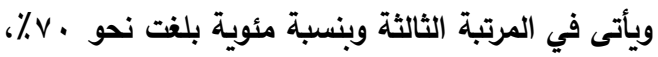

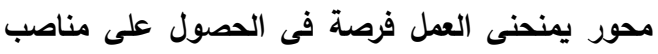

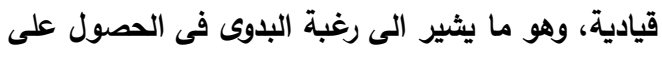

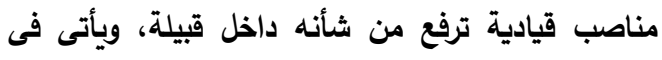

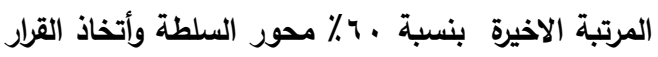

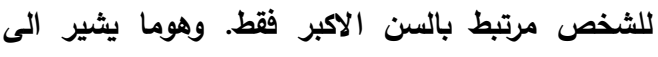

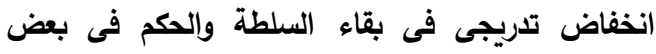

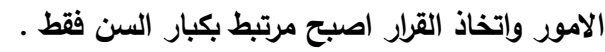

يتضح من النتائج الواردة بالجدول رقم (V) ان المهنة لها دورا هام فى الحصول على لإنى المكانه الاجتماعية لاى الاثخاص وذلك بنسبة كلية بلفت نحو

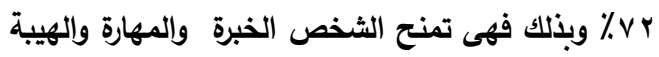
الاجتماعية والقدرة على اتخاذ القرارات المجتمعية وتحسن الاخل مما ينعكس على المكانة الثخصية للاففراد داخل

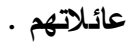

\section{r- (المكانة الإجتماعية}

توضح النتائج الواردة بجدول رقم (v) والمتعلقة بالمحاور السته لاففع الحصول على المكانة الاجتماعية

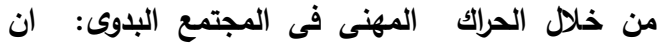

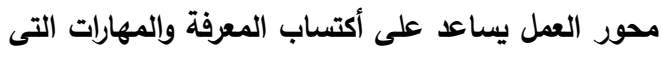

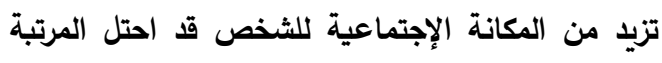

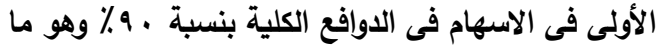
يوضح الهية العمل لاى البدوى فى فلى زيادة مكانة

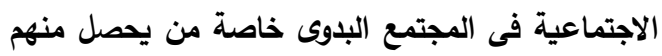

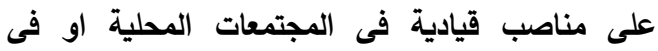
المحافظة ومراكز المعلومات، وجاء في المرتبة الثانية

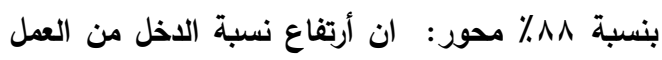

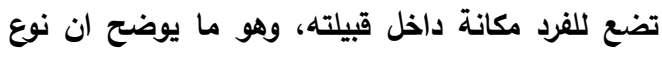

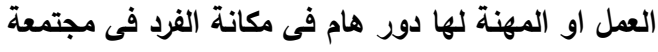
فأنه يستطع جمع افراد كثيرين فى منزلة وضيافتهر وبحكم طبيعة عملة يستطع وزن العديد من الامور 


\section{A. A. Refae}

جدول رقم ( V ): المتوسطات الحسابية والاوزان النسبية لدوافع المكانة الاجتماعية .

\begin{tabular}{|c|c|c|c|c|}
\hline المرتبة & $\%$ & متوسط & البيـان & s \\
\hline$r$ & $v$. & r.11 & يمنحنى العمل فرصة فى الحصول على مكانه قيادية & 1 \\
\hline ○ & r & 1.9 & يمنحنى التعليم خبرة فى مجال تخصصى أفيد بها عشيرتى وعائلتى & r \\
\hline r & $\wedge \wedge$ & r. 44 & أرتفاع نسبة الاخل من العمل تضع للفرد مكانة داخل قبيلته & $r$ \\
\hline 9 & 9. & 1.1 & السلطة وأتخاذ القرار للشخص مرتبط بالسن الاكبر فقط & $\varepsilon$ \\
\hline$\varepsilon$ & 94 & r.. & مكانة الثخص وهيبته الإجتماعية مرتبطة بمكانة قبيلته وعمله & - \\
\hline 1 & 9. & r.v & يساعد العمل على إكتساب مهارات معرفية تزيد من مكانته الثخصية والإجتماعية & 9 \\
\hline & VY.AT & P.19 & المتوسط العام & \\
\hline
\end{tabular}

المصدر: جمعت وحسبت من بيانات الدراسة الميدانية بأستخدام الحاسب الالى

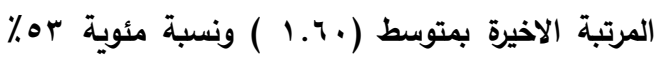

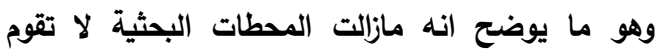
بدورها الكافى فى تنمية وتطوير المجتمع البدوى.

يتضح من النتائج الواردة بالجدول رقم (^) ان

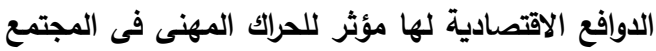

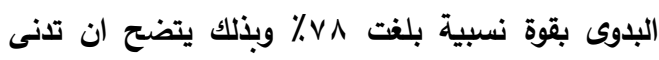
العائد من الحرف التقليدية والرغبة فى تحسين مستوى المعيثة والاخل كان دافع للعمل بمهن متنوعة وحديثة اخرى لتحسين مستوى المعيشة لاى البدو.

ثامنا: أستخدام التكنولوجيا:

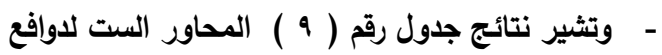
استخدام التكنولوجيا للحراك المهنى فى المجتمع البدوى الى ان: محورى رغبة المبحوثين فى أستخدام

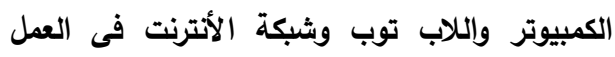
وكنلك رغبة الأبناء فى أستخدام التكنولوجيا الحديثة فى الاتصالات فى العمل فى المرتبة الاولى بنسبة

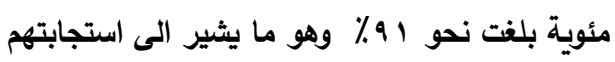

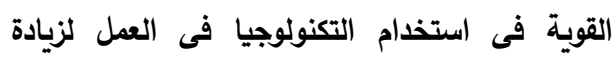

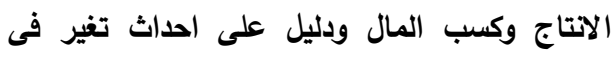

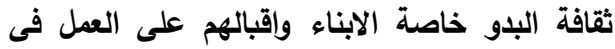
بعض المهن التى تتطلب ذلك، ثم جاءت فى المرتبة
سابعا: الدوافع الاقتصادية للحراك المهنى بالمجتمع

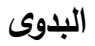

توضح النتائج الواردة بجدول رقم (^) المحاور

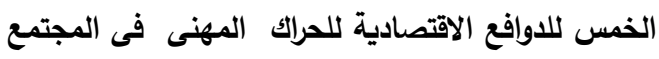
البدوى وتثير النتائج الى ان محور أرتفاع العائد المادى لاديه

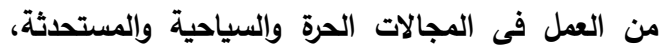

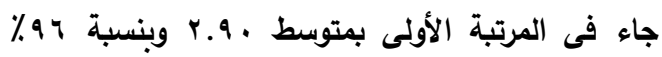

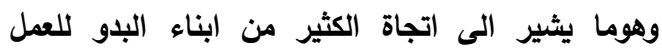

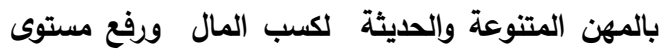
المعيثة وترك بعض المهن المتوارثة من الاباء و

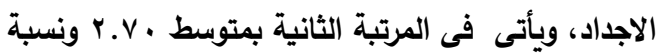

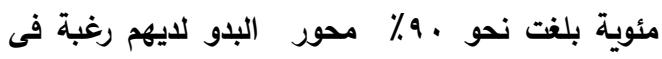
تحسن مستوى الاخل من العمل بمهن غير تقليدية. وهوما يثير الى التغير الثقافى فى المجتمع البدو خاصة فى المهن، ثم تاتى فى المرتبة الثالثة بمتوسط (Y.०V)

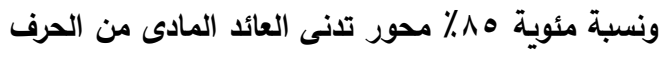

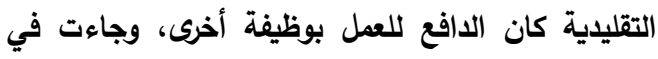

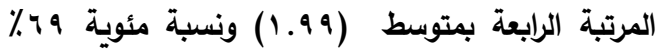

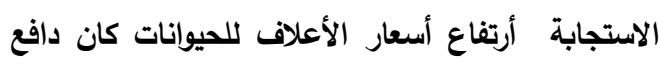

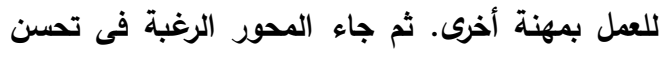

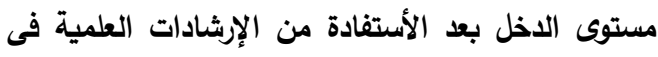

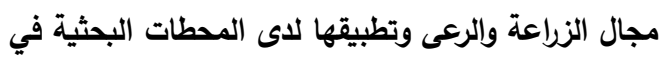




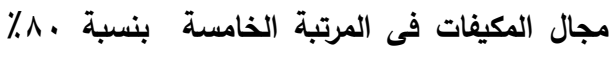
وهو ما يثير الى استخدام بعض البذو للتكيفات

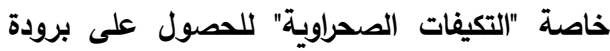
الجو فى بعض شهور الصيف شديدة الحرارة، ثم جاءت في المرتبة الأخيرة المحور الرغبة في أمتلاك

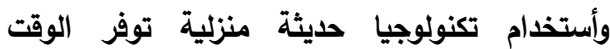
والمجهود צv\% وهو ما يوضح مدى ادراكهم باهمية استخذام التكنولوجيا الحديثة فى الاحتياجات المنزلية.
الثالثة المحور رغبة المبحوثين فى العمل بمهن غير تقليدية فى المجتمع البدوى بعد تعلمهم بنسبة مئوية ج \%٪، وهوما يشير الى تقبل الاجيال الجديدة للمهن المستحدثة ورفض البعض منهم المهن المتوارثة

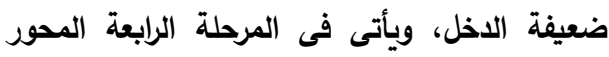

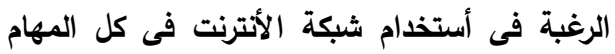
بنسبة ه9\% وهو ما يوضح رغبة البدو فى الاطلاع على كل جليد واستخدام التكنولوجيا الحديثة. وجاء

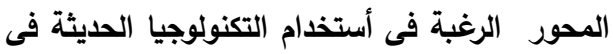

جدول رقم ( ^ ): يوضح المتوسط الحسابى والاوزان النسبية للدوافع الاقتصادية .

\begin{tabular}{|c|c|c|c|c|}
\hline 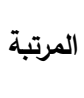 & $\%$ & متوسط & البيـان & p \\
\hline r & ^。 & r.०V & تدنى العائد المادى من الحرف التقليدية كان دافع للعمل بوظيفة أخرى & 1 \\
\hline$\varepsilon$ & צי & 1.99 & أرتفاع أسعار الأعلاف للحيوانات كان دافع للعمل بمهنة أخرى & r \\
\hline r & 9. & r.v. & الرغبة فى تحسن مستوى الدخل من العمل بمهن غير تقليدية & r \\
\hline 0 & or & 1.7 & والرعى وتطبيقها فى تحسن مستوى الاخل بعد الأستفادة من الإششادات العلمية فى مجال الززاعة & $\varepsilon$ \\
\hline 1 & 94 & r.9. & إرتفاع مستوى الاخل نتيجة للعمل فى مجال السياحة وخدماتها & - \\
\hline & $\vee \wedge$ & r.ro & المتوسط العام & \\
\hline
\end{tabular}

المصدر: جمعت وحسبت من بيانات الدراسة الميدانية بأستخدام الحاسب الالى

جدول رقم ( 9 ) : المتوسط الحسابى والاوزان النسبية لدوافع استخدام التكنولوجيا .

\begin{tabular}{|c|c|c|c|c|}
\hline المرتبة & $\%$ & متوسط & البيــان & r \\
\hline 1 & $9 \wedge$ & r.90 & أستخدام التكنولوجيا الحديثة فى الاتصالات فى العمل. & 1 \\
\hline$r$ & 97 & r.^^ & العمل بمهن غير تقليدية فى المجتمع البدوى بعد تعلمهم & r \\
\hline 1 & $9 \wedge$ & $r .90$ & رغبة الأبناء في إستخدام الكمبيوتر والللاب توب فى العمل & $r$ \\
\hline 9 & $v^{4}$ & r.T. & إمتلاك وأستخدام أجزة تكنولوجية حديثة فى المنزل توفر الوقت والمجهود & $\varepsilon$ \\
\hline$\varepsilon$ & 90 & r.^॰ & أستخام شبكة الأتترنت فى كل المهام & $\bullet$ \\
\hline \multirow[t]{2}{*}{$\bullet$} & $\wedge$. & r.\& & أستخام الأجهزة الحديثة فى مجالات العمل لتوفير الوقت والجهـ وزيادة معدل الأنتاج & 7 \\
\hline & $9 . .0$ & r.vr & المتوسط العام & \\
\hline
\end{tabular}

المصدر: جمعت وحسبت من بيانات الاراسة الميدانية بأستخام الحاسب الالى 
r^\% ، وهو ما يوضح تعرض المجتمع البدوى الى تغيرات مناخية ذات تأثير قوى على بعض الزراعات نتيجة لمواسم الجفاف مما ادى الى ضعف الناتج من المحاصيل مما اثر على دخل الاسرة وانخفاض مستوى معيشتها، وجاء فى المرتبة الثالثة بنسبة

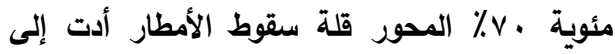
تقليص حجم المراعى التى يتغذى عليها الحيوانات وهو ما يثير الى قلة الثروة الحيوانية مما أضطرن البعض منهم للبحث عن وظيفة أخرى، ويأتى فى المرتبة الرابعة بنسبة بـ٪ المحور نقصان الأراضي الزراعية بسبب تحويلها إلى أراضي سكنية

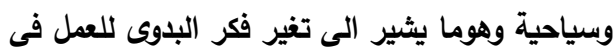
تجارة الاراضى والسياحة، ويأتى فى المرتبة الاخيرة بنسبة وه \% المحور غياب دور الأرشاد الزراعى فى لمى مقاومة الآفات. وهو ما يشير الى ان جوهر المشكلة تنحصر فى بعض سنوات الجفاف وضعف دور

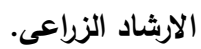

يتضح من النتائج الواردة بالجدول رقم (9) ان دوافع استخدام التكنولوجيا تشكل عامل هام للحراك المهنى فى المجتمع البدوى بقوة نسبية بلغت و ٪، وبذلك

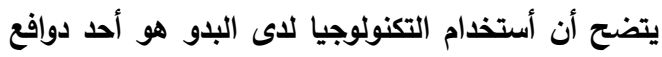
الحرالك المهنى لما لها من دور هام فى توفير سبل الراحة والوقت والمجهود وأيضاً وسيلة هامة للنقل والأتصالات والمعرفة وأكتساب المهارات من خلال شبكة الأنترنت.

\section{تاسعا: الدوافع البيئية} - توضح النتائج الوارده بجدول رقم (· (1) المحاور

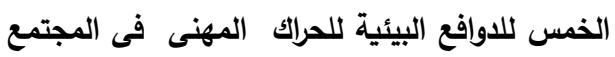
البدوى الى ان: محور قلة حجم المراعى الطبيعية أدت إلى نقصان أعداد الحيوانات ، أتى فى المرتبة

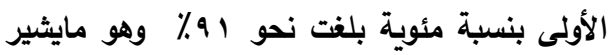
إلى ان قلة سقوط الامطار فى بعض المواسم أنعكست بلورها على تغذية الاسرة ودخلها. ثم يأتى فى المرتبة الثانية المحور تدهور بعض المحاصيل الرئيسية بسبب التغيرات المناخية، بنسبة مئوية

جدول رقم ( 1 ): المتوسط الحسابى والاوزان النسبية للدوافع البيئية.

\begin{tabular}{|c|c|c|c|c|}
\hline 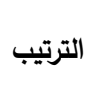 & $\%$ & متوسط & البيــان & م \\
\hline$r$ & $v$. & r.l & للبحث الأمطار أدت إلى قلة حجم المراعى التى يتغذى عليها الحيوانات مما أضطرنى & 1 \\
\hline 1 & 91 & Y.Vo & قلة حجم المراعى أدت إلى نقصان أعداد الحيوانات مما أنعكس على دخل الأسرة. & r \\
\hline$\varepsilon$ & זי & 1.9 & نقصان الأراضى الزراعية بسبب تحوبلها إلى أراضى سكنية وسياحية. & r \\
\hline r & Ar & r.乏^ & تدهور بعض المحاصيل بسبب التغيرات المناخية وزحف الرمال. & $\varepsilon$ \\
\hline \multirow[t]{2}{*}{0} & oq & I.VV & غياب دور الأرشاد الزراعى فى مقاومة الآفات & ○ \\
\hline & Vr & r.r & المتوسط العام & \\
\hline
\end{tabular}

المصدر : جمعت وحسبت من بيانات الدراسة الميدانية بأستخدام الحاسب الالى 


$$
\begin{aligned}
& \text { مستفيدة مـن المشــاريع التنمويـة التى تحـدث فى }
\end{aligned}
$$

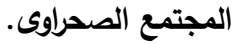

r- اوضحت نتائج الاراسـة ان أن نسبة الفئسة الاقل فى

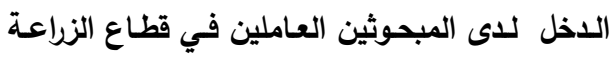
والوظيفة والعمل الحرفى حيث انحصرت هذة الفئات بين الاقل والاوسط دخـلا فـى حين سجلت الفئسة الاكثر دخــلا لـلدى المبحـوثين العـاملين في قطــاع

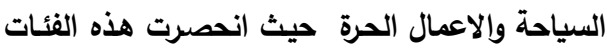

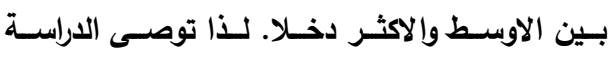
بضـرورة الاهتمـام بالقطـاعين" السـياحة ، الاعمـال الحرة " لما لهم من دور هام فى زيادة دخل المواطن البدوى وارتفاع المستوى المعيثى والثقافى لله. ع - بينت نتائج الداسـة وجود حراك مهنى صـاعد للاى

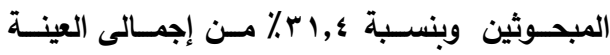

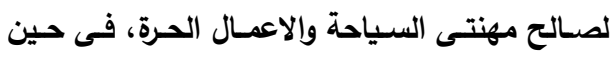

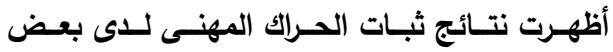
المبحوثين وبنسبة مئوية ؛. \^٪ من فئة المزارعين

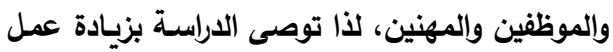
المشروعات التتمويـة فى منطقـة الدراسـة فـى مجـال السياحة والاعمال الحرة.

ه- اكدت نتائج الدارسة ان للحراك المهنى لـه دور هام لاحاث الانفتاح الجفرافى والثقافى بقوة نسبية بلغت

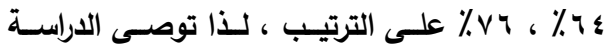

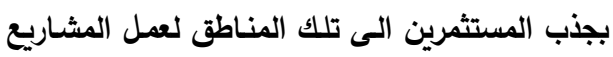

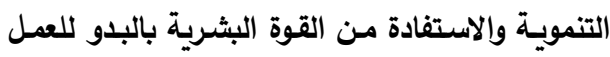

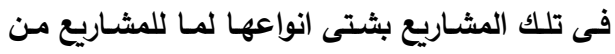
دور هام فى الانفتاح الجغرافى والثقافى للبدو.

7-بينت نتائج الدراسـة ان التعليم يثكل دافع رئيسى التحس

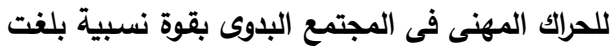

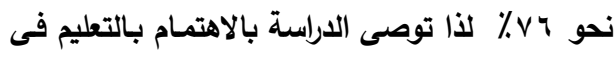
المجتمع البدوى فى مختلف انواعة لنشأ جيل متعدد
يتضح من النتائج الواردة بالجدول رقم (•) ان الدوافع البيئية لها دور مؤثر للحراك المهنى فى المجتمع البدوى بلفت نسبة rv\% حيث ان التغيرات المناخية والجفاف والتصحر تثكل دافع قوى لتغير المهنة بحثا عن مستوى معيشى افضل وزيادة الاخل. توصيات الدراسة فـى ضـوء النتائج التى تـم التوصل اليها فـى هذه الاراسة يمكن الخروج بمجموعة من التوصيات التى قد تفيد المهتمين بقضايا الحراك المهنى فى المجتمع البدوى

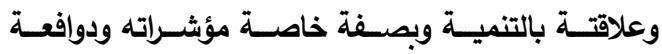
الاجتماعية والاقتصادية والبيئية.

1-حيث اوضحت نتائج الدراسة انخفاض مستوى التعليم لاى الاباء والامهات حيث بلغت نسبة الامية

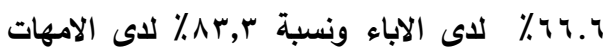

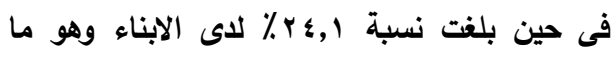
يوضح وجود فارق بين الجيلين فى المستوى لإئاء التعليمى لصالح جيل الابناء لذا توصى الدراسة ضرورة توفير مشاريع تنموية تخدم القرى البدوية،

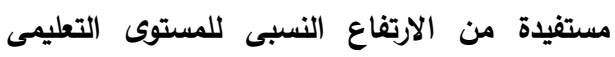

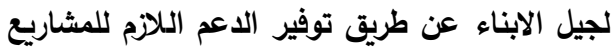

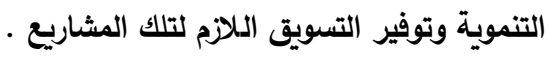
ץ-بينت نتائج الدراسة ان نسبة العاملين بمهنة الرعى

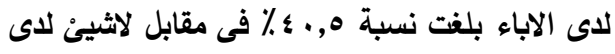

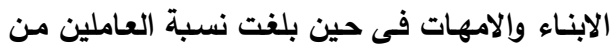

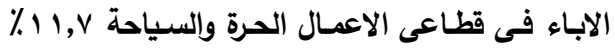

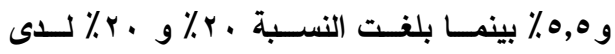

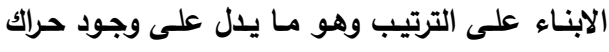

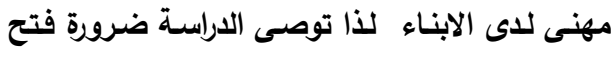

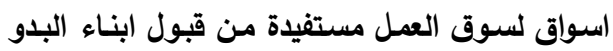
التغير الاجتماعى والثقافى والاقتصادى والذى انعكس فـى تغيـر ابنـاء البـدو لمهنــة الاجـداد او تطويرهـا 


\section{A. A. Refae}

الجهاز المركزى للتعبئة العامة والاحصاء، مصر فى ارقام

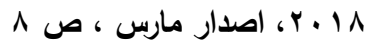

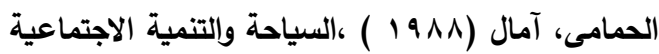

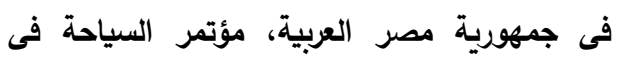

مصر ، إقتصاديات وإدارتها، جامعة المنصوره.

رشوان ، حسين عبد الحميد ( (99v)، العلاقات الإنسانية فى مجالات علم النفس والإجتماع وعلم

الإدارة، الإسكندرية، المكتب الجامعى الحديث.

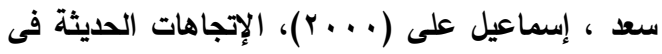

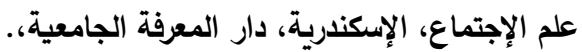

شاش، منير أحمد (؟9 9 1) إستراتيجية التنمية الزراعية

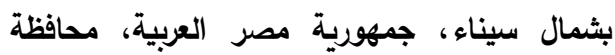

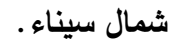

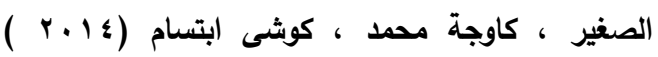

الحراك الاجتماعى وعلاقتة بالمتغيرات المجتمعية

للمجالات الاجتماعية فى المدينة الجزائرية ، دراسة الجئة

ميدانيو لترمواى ورقله ، مجلة العلوم الآسانية

والاجتماعية ، عدد خاص بملتقى الدولى تحولات

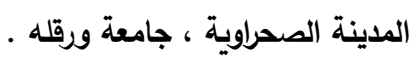

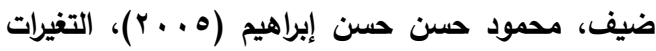

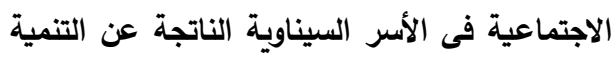

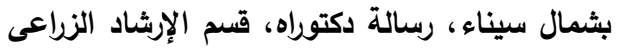

والمجتمع الريفى، كلية الزراعة، جامعة القاهرة

الطيب ، مولود زايد ، دور الحراك الاجتماعى فى

الحصول على المكانة الاجتماعية وعلاقة ذلك ببنية

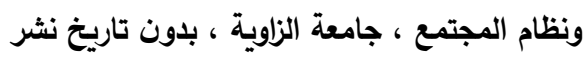

العادلي، فاروق محمد - علم الاجتماع البدوي- دار

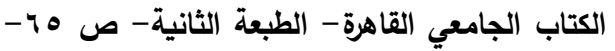

.79

عبد الرحمن، عبد الله محد (ץ.... مريم أحمد

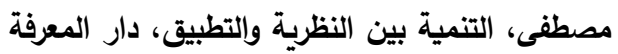

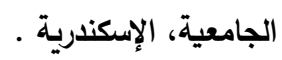

المواهب والمهارات التى يحتاجها القوى العاملة فى

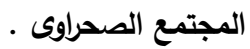

V- اوضحت الدراسة ان العملية الاقتصادية تثكل دافع

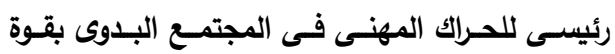

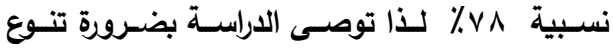

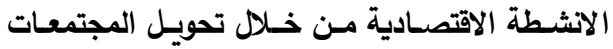

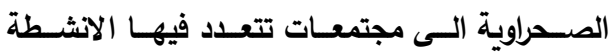

الاقتصادية ما بين زراعية وصناعية وبيئية وخدمية

وسياحية وزيادة الاستثمارات فى مجالات غير زراعية

يسهم فيها القطاع العام والخاص والبنوك.

^- اوضحت الدراسة ان استخدام التكنولوجيا تثكل دافع

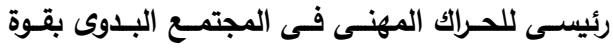

نسبية بلغت نحو ، 9\% لذا توصى الدراسـة بضرورة

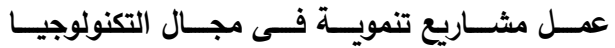

واستخذاماتها مستفيدة برغبة البدو المرتفعة فى هذا

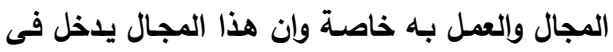

كافة الانثطة الاقتصادية .

قائمة المراجع العربية والاجنبية

اولا: المراجع العربية

أبو زيد، أحمد (9Av ) ، البناء الاجتماعي، مدخل

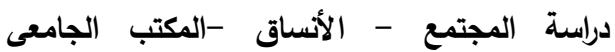

الحديث، الإسكندرية.

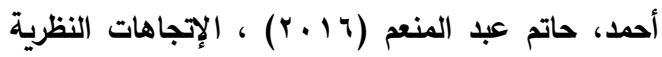

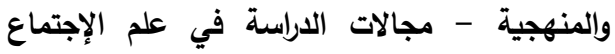
البيئي، بورصة الكتب.

إسماعيل، فاروق مصطفى (.999) ، التغير والتنمية

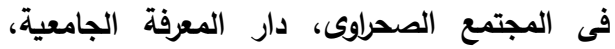
الإسكندرية،.

حجاج، وفاء و أرناؤوط ،محمد السيد (10 + ب)، التنمية

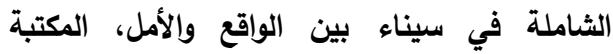

الأكاديمية. 
مركز المعلومات ودعم إتخاذ القرار، محافظة جنوب

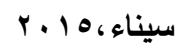

ثانيا : المراجع الاجنبية

- Keller,J .W., Rural Development in the United States : Connecting Theory, Practice, and Possibilities, Journal of American Planning Association, Winter. Vol.6, 1996.

- : https://www.alukah.net/fatawa counse Is/0/14371/\#ixzz5mwoySuVu

http://www.roayapedia.org/wiki/index.ph p
عبد الرحمن، عبد الله محمد، (1991) التوطين والتنمية

فى المجتمعات الصحراوية، دار المعرفة الجامعية، الإسكندرية.

عوض، السيد حنفى (1999) علم الإنسان ، ظافر

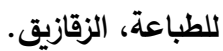

الغامدى، على (Y.11) نظرية بياجيه وتطبيقاتها

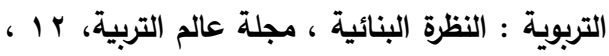

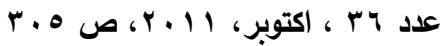

غيث، محمد عاطف، (199 ) ) علم الإجتماع، دار المعرفة الجامعية، الإسكندرية، ؛ 99 19.

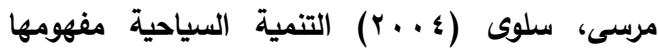
ومحدداتها وأهميتها مع الإثشارة إلى حركة السياحة المصرية، معهذ التخطيط القومى، القاهرة. 


\title{
INDICATORS AND MOTIVES OF OCCUPATIONAL MOBILITY IN THE BEDOUIN COMMUNITY
}

\author{
Ahmed Anwar Refae \\ Department of Social Studies - Desert Research Center
}

\begin{abstract}
The study aimed to identify Indicators of the social and Occupational mobility in the Bedouin community through two generations (sons, parents and mothers) as well as to identify type of the professional mobility and also to identify the motives of professional mobility and to achieve the objectives of the study. The questionnaire was used by individual interviews to collect data from two villages in Ras Sidr Center and two other communities at Sharm El-Sheikh in South Sinai government, through a random sample of 120 researchers and distributed on five occupations with 24 individuals for each profession. Many statistical methods were used to analyze the data and to clarify the results of the study are descriptive statistics methods (repetitions, percentages, arithmetic mean, Weighted average, weighted weight) The study reached several results, the most important of which are:
\end{abstract}

1. The percentage of illiteracy among the generation of parents reached $66.6 \%$ for fathers, $83.3 \%$ for mothers, while the illiteracy rate among the generation of sons decreased to $24.1 \%$ of the sample size. The results also indicate that the increase in rates in the two categories of the most income of the five income levels reached by $31 \%$ Of the sample size in the generation of sons compared to 1.3 of the size of the sample in the generation of parents as well as in the use of computer, which amounted to about $69 \%$ of the size of the sample in sons compared to $10 \%$ of the sample size in the parents which indicates the existence of an increasing social mobility upward in the index of: education, income, technology use for the generation of children.

2. The increase in illiteracy rate among the generation of the sons in each of the following occupations: Agriculture, job and handicraft, 45\%, 37\%, 37\% respectively of the sample size for each of them while illiteracy decreased to $0 \%$ for those who work in tourism career and free work. The results also indicate that the income of tourism and business professions in the two highest income categories of the five income levels increased by $37 \%$ and $45 \%$, and $37 \%$ and $37 \%$, respectively, while the percentage of other professions in the two highest income categories reached $0 \%$, while the results indicate the increase in the percentage of computer use in the professions of entrepreneurship, tourism and job to reach $91 \%, 87 \%$ and $72 \%$ respectively which indicates the existence of an increasing social mobility for the professions of entrepreneurships and tourism in all of the following indicators: education, income, the use of technology and the preference of the sons to work in new occupations rather than the careers of fathers and grandparents.

3. The results of the study related to the motives of the professional mobility in the Bedouin community indicates the following:

A - The social motives : Both of education and social status formed a major motive for professional mobility in the Bedouin society, with a percentage of about $76 \% 72 \%$, of the total sample of study. 
B- The economic motives of professional mobility in the Bedouin society contributed to a relative degree of about $78 \%$ of the total sample of the study

C- The environmental motives strongly shared in the professional mobility in the Bedouin society with about $73 \%$ of the study sample

$D$ - The use of technology motives contributed to the professional mobility in the Bedouin society by about $90 \%$ of the study sample.

Key words: Social mobility, occupational mobility, geographical openness, cultural openness

$$
\begin{aligned}
& \text { السادة المحكمين } \\
& \text { أ.د/ ياسمين أحمد عــــار قيم الإرشاد الزراعى - مركز الصحراء - المطرية }
\end{aligned}
$$

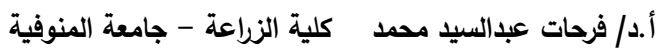

